\title{
THE ROLE OF CHARGE-TRANSFER COMPLEXES IN CYCLOCOPOLYMERIZATION
}

\author{
GEORGE B. BUTLER \\ Department of Chemistry, University of Florida, Gainesville, \\ Florida 32601, U.S.A.
}

\begin{abstract}
Previous work from this laboratory has shown that certain 1,4-dienes which readily undergo cyclocopolymerization with certain alkenes also form chargetransfer complexes with the same alkenes. The results observed and the proposed cyclocopolymerization mechanism are consistent with participation of the charge-transfer complex as a distinct species in the copolymerization. This paper includes a discussion of an investigation to determine whether there was a dilution effect on the relative reactivities of the monomers in support of the charge-transter participation concept, and whether the results of a suitable terpolymerization study would also support this postulate. In the system, divinyl ether-fumaronitrile, the maximum rate of copolymerization occurred at a monomer feed ratio of $1: 2$ and the composition of the copolymer was also $1: 2$ at a total monomer concentration of 3 moles/1. However, when the concentration was progressively lowered to $0.5 \mathrm{ml}^{-1}$, using the same monomer feed ratio, the fumaronitrile content of the copolymer decreased in a linear manner. In a series of terpolymerization experiments using the system, divinyl ethermaleic anhydride-acrylonitrile, it was shown that the divinyl ether-maleic anhydride ratio in the terpolymer was always greater than $1: 1$ and had an upper limit of $1: 2$, regardless of the feed ratio of the termonomers. These results are consistent with the participation of the charge-transfer complex of divinyl ether and maleic anhydride in a copolymerization process with either maleic anhydride or acrylonitrile as the comonomer. Other systems which support these concepts are also presented. This paper emphasizes theoretical aspects of the problem rather than attempting to summarize the many examples of comonomer systems which have been found to participate in this interesting copolymerization.
\end{abstract}

\section{INTRODUCTION}

Since the first observation in 1951 by Butler and Ingley ${ }^{1}$ that diallyldialkylammonium salts led to saturated linear polymers rather than crosslinked structures as predicted by existing theories ${ }^{2}$, and the proposal ${ }^{3}$ and proof of the alternating intra-intermolecular polymerization mechanism ${ }^{4}$ to account for these results, numerous 1,6-dienes have been shown to proceed by this cyclopolymerization mechanism ${ }^{5}$, thus establishing the mechanism as a general propagation course for this type of monomer. In 1958, Butler $^{6,7}$ reported an example of bimolecular alternating inter-intramolecular chain propagation, the mechanism of which is similar to the cyclopolymerization mechanism reported above. This process is now commonly referred to as cyclocopolymerization ${ }^{8}$. This unique copolymerization is illustrated in equation 1 . 
<smiles>[Y]/C=C\C=C/[Y]</smiles>
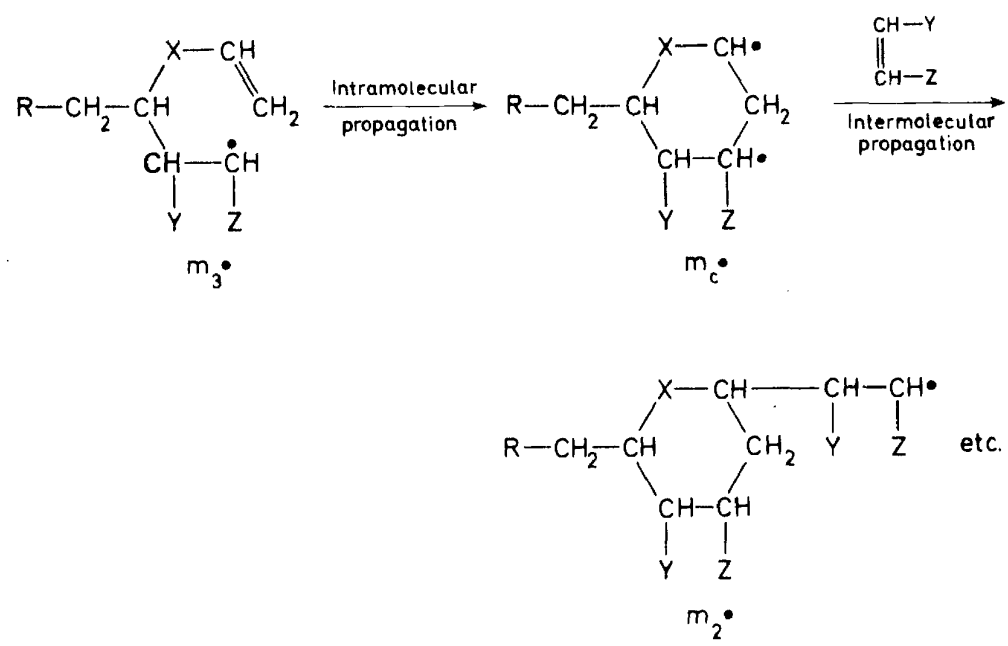

The first example reported was the copolymerization of divinyl ether and maleic anhydride. A wide variety of additional examples of cyclocopolymerization of 1,4-dienes and alkenes were reported in subsequent publications $\mathrm{s}^{9,10}$. Equation 2 illustrates a generalized structure for the copolymers and some additional specific structures.

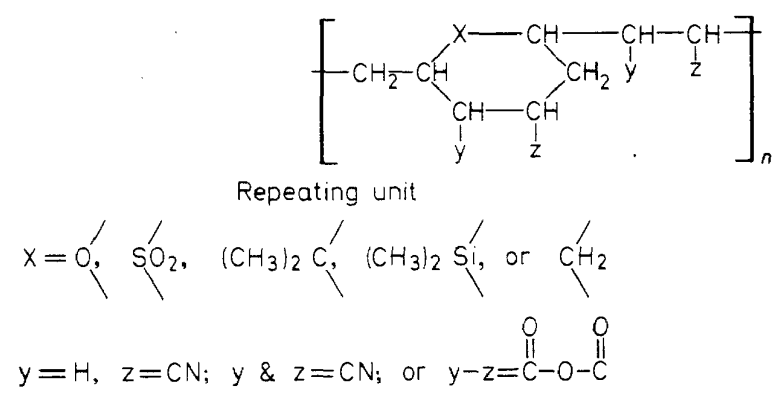

\section{THEORY AND MECHANISM}

Barton, Butler and Chapin ${ }^{8}$ have developed a general copolymer composition equation for cyclocopolymerization of 1,4-dienes $\left(\mathbf{M}_{1}\right)$ and monoolefins $\left(\mathrm{M}_{2}\right)$. The kinetic scheme considered by these authors is shown in equations 3-11. 


$$
\begin{aligned}
& \mathrm{m}_{1}^{\cdot}+\mathrm{M}_{1} \stackrel{k_{11}}{\rightarrow} \mathrm{m}_{1}^{\cdot} \\
& \mathrm{m}_{1}^{\cdot}+\mathrm{M}_{2} \stackrel{k_{12}}{\rightarrow} \mathrm{m}_{3}^{\cdot} \\
& \mathrm{m}_{3}^{\cdot} \stackrel{k_{\mathrm{c}}}{\rightarrow} \mathrm{m}_{\mathrm{c}}^{\cdot} \\
& \mathrm{m}_{3}^{\cdot}+\mathrm{M}_{1} \stackrel{k_{31}}{\rightarrow} \mathrm{m}_{1}^{\cdot} \\
& \mathrm{m}_{3}^{\cdot}+\mathrm{M}_{2} \stackrel{k_{32}}{\rightarrow} \mathrm{m}_{2}^{\cdot} \\
& \mathrm{m}_{\mathrm{c}}^{\cdot}+\mathrm{M}_{1} \stackrel{k_{\mathrm{c}}}{\rightarrow} \mathrm{m}_{1}^{\cdot} \\
& \mathrm{m}_{\mathrm{c}}^{\cdot}+\mathrm{M}_{2} \stackrel{k_{\mathrm{c} 2}}{\rightarrow} \mathrm{m}_{2}^{\cdot} \\
& \mathrm{m}_{2}^{\cdot}+\mathrm{M}_{1} \stackrel{k_{21}}{\rightarrow} \mathrm{m}_{1}^{\cdot} \\
& \mathrm{m}_{2}^{\cdot}+\mathrm{M}_{2} \stackrel{k_{22}}{\rightarrow} \mathrm{m}_{2}^{\cdot}
\end{aligned}
$$

$\mathrm{M}_{1}$ is the diene $\mathrm{CH}_{2}=\mathrm{CH}-\mathrm{X}-\mathrm{CH}=\mathrm{CH}_{2}$, where $\mathrm{X}$ is $\mathrm{CH}_{2}, \mathrm{O}, \mathrm{SO}_{2}$, etc. $\mathrm{M}_{2}$ is the mono-olefin, $\mathrm{CHY}=\mathrm{CHZ}$. The $\mathrm{m}_{1}^{*}$ is the radical $m \mathrm{CH}_{2}$ $\mathrm{CH}-\mathrm{X}-\mathrm{CH}=\mathrm{CH}_{2}, \mathrm{~m}_{2}^{*}$ is the radical $m \mathrm{CHY}-\dot{\mathrm{C}} \mathrm{HZ}, \mathrm{m}_{3}^{*}$ is the radical

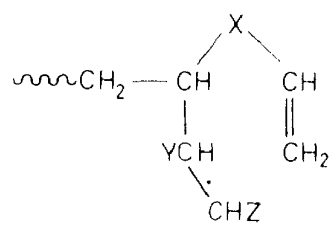

and $m_{c}^{*}$ is the cyclized radical

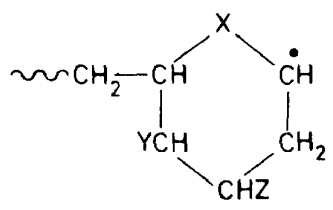

The fate of the intermediate radical, $\mathrm{m}_{3}^{*}$, is governed by the relative rate of cylization $\left(k_{\mathrm{c}}\right)$ and addition to monomers $1\left(k_{31}\right)$ and $2\left(k_{32}\right)$.

Although a six-membered ring is normally the most likely product of cyclization of $\mathrm{m}_{3}^{*}$, if the terminal methylene in $\mathrm{m}_{3}^{*}$ were hindered by bulky substituents or if it were conjugated with an aromatic group, a five-membered ring might be favoured. This should not however influence the overall kinetics.

By neglecting penultimate group effects and crosslinking reactions, and making the usual steady state assumption equation 12 was derived.

$n=\frac{\left(1+r_{1} x\right)\left\{1 /\left[\mathrm{M}_{2}\right]+(1 / a)\left(1+x / r_{3}\right)\right.}{(1 / a)\left\{\left(x / r_{3}\right)+\left(r_{2} / x\right)+2\right\}+\left(1 /\left[\mathrm{M}_{2}\right]\right)\left\{1+\left(1+r_{2} / x\right)\left(1+r_{c} x\right)^{-1}\right\}}$

where $x=\left[\mathrm{M}_{1}\right] /\left[\mathrm{M}_{2}\right], r_{1}=k_{11} / k_{12}, r_{2}=k_{22} / k_{21}, r_{3}=k_{32} / k_{31}, r_{\mathrm{c}}=k_{\mathrm{c} 1} / k_{\mathrm{c} 2}$, $a=k_{\mathrm{c}} / k_{32}$.

Equation 12 is a differential copolymer composition equation which is applicable to the proposed scheme of cyclocopolymerization. The equation 
may be applied by putting $n \simeq\left[\mathrm{m}_{1}\right] /\left[\mathrm{m}_{2}\right]$, the fractional ratio of monomers combined in the copolymer at low conversions.

A similar equation (equation 13) was derived relating the relative rate of addition of diene and the rate of cyclization:

$$
\begin{aligned}
& \frac{\mathrm{d}\left[\mathrm{M}_{1}\right]}{\mathrm{d}\left[\mathrm{M}_{\mathrm{c}}\right]}=\frac{\left(k_{11}+k_{12}\right)}{k_{12} k_{\mathrm{c}}}\left(k_{31}+k_{32}+k_{\mathrm{c}}\right) \\
& \quad=\left(r_{1} x+1\right) \frac{\left[\mathrm{M}_{1}\right]}{r_{3} a}+\frac{\left[\mathrm{M}_{2}\right]}{a}+1
\end{aligned}
$$

Equation 13 applies at low conversions where $\mathrm{d}\left[\mathrm{m}_{1}\right] / \mathrm{d}\left[\mathrm{m}_{\mathrm{c}}\right] \simeq\left[\mathrm{m}_{1}\right] /\left[\mathrm{m}_{\mathrm{c}}\right]$, the ratio of the total fraction of diene (unsaturated and cylic) to the fraction of diene in cyclized units, in the copolymer.

If precise analytical methods are available for determining both the total fraction of diene in the copolymer and the fraction of either cyclic units or pendant vinyl groups, then by making a series of such measurements for different initial monomer feed compositions, values for $r_{1}, r_{3}$, and $a$ could be obtained from equation 13. Then the remaining two parameters, $r_{2}$ and $r_{\mathrm{c}}$ could be obtained from equation 12 .

In certain special cases equation 12 may be approximated to simpler forms, as in the following examples:

(a) If $k_{\mathrm{c}} \gg k_{32}$ so that $a$ is very large and cyclization is the predominant reaction of the radicals $m_{3}$, then equation 12 gives:

$$
n=\frac{\left(1+r_{1} x\right)\left(1+r_{\mathrm{c}} x\right)}{r_{\mathrm{c}} x+\left(r_{2} / x\right)+2}
$$

This is equivalent to considering the addition of mono-olefine to diene radicals to be a concerted bimolecular step proceeding through a cyclic transition state and producing the cyclic repeating unit.

(b) If in addition there is a strong alternating tendency so that $\left(r_{1}, r_{2}, r_{\mathrm{c}}\right) \rightarrow 0$ then equation 14 reduces in the limit to $n=1 / 2$. This predicts an alternating copolymer composition of $2: 1$ molar in contrast to $1: 1$ for the similar limiting case of the classical binary copolymer composition equation.

(c) If the diene has a negligible tendency to add to its own radicals and $r_{1} \simeq r_{\mathrm{c}} \simeq 0$, and there is also predominant cyclization, then equation 14 gives:

$$
n=1 /\left(\frac{r_{2}}{x}+2\right)
$$

A plot of $1 / n$ against $1 / x$ should be linear with a slope $r_{2}$ and an intercept 2.0.

The application of each of these special cases of the theory was shown by these and subsequent authors. Figure 1 shows an example of Special Case (a). The copolymerization of divinyl ether and acrylonitrile is an example of a system which does not form constant composition copolymers but where cyclization predominates over side reactions (branching or crosslinking) and was shown to be described by equation 14 at low conversions.

Figure 1 illustrates the best fit of the data for this system to equation 14, 
obtained using a digital computer method similar to that applied by Tidwell and Mortimer ${ }^{12}$ for the classical binary copolymer composition equation.

The method is essentially a least squares fit of the data to equation 14 by a non-linear (Gauss-Newton) procedure, starting from initial estimates of the values of $r_{1}, r_{2}$, and $r_{\mathrm{c}}$ obtained manually by curve fitting.

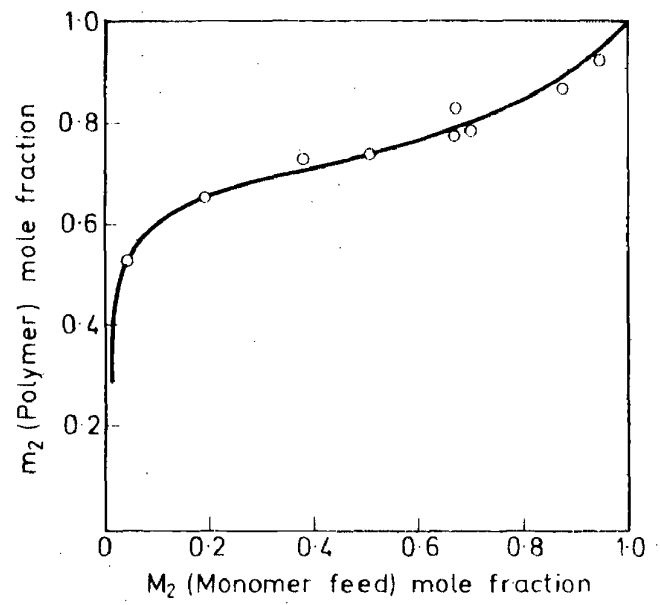

Figure 1. Divinyl ether $\left(\mathrm{M}_{1}\right)$-acrylonitrile $\left(\mathrm{M}_{2}\right)$ copolymers. Points are experimental. Line calculated for: $r_{1}=0.024 ; r_{2}=0.938 ; r_{c}=0.017$.

The solid line in Figure 1 is drawn for $r_{1}=0.024, r_{2}=0.938$, and $r_{c}=0.017$. These are the values for which $\Sigma \Delta^{2}$, the sum of the squares of the differences between observed and computed values of $n$ was a minimum. For the initial estimates $r_{1}=0 \cdot 04, r_{2}=0 \cdot 90$, and $r_{\mathrm{c}}=0 \cdot 01, \Sigma \Delta^{2}$ was reduced from 0.246462 to 0.0851882 in three iterations of the computing cycle.

Figure 2 shows an example of Special Case (b) in which an alternating copolymer composition of 2:1 molar in $\mathbf{M}_{2}$ and $\mathbf{M}_{1}$ was observed. Divinyl ether-N-phenylmaleimide and 1,4-pentadiene-maleic anhydride give similar monomer-polymer composition plots and represent further examples of Special Case (b).

The system, 1,4-pentadiene-acrylonitrile was shown to be an example of Special Case (c). Since 1,4-pentadiene does not homopolymerize under the conditions used so that $r_{1}=0$, but cyclization is predominant, equation 15 was predicted to fit the experimental data. Figure 3 confirms this prediction.

In Figure 3 a plot is shown of $1 / n\left(=\left[\mathrm{m}_{2}\right] /\left[\mathrm{m}_{1}\right]\right)$ against $1 / x\left(=\left[\mathrm{M}_{2}\right]\right.$; $\left[\mathrm{M}_{1}\right]$ ) for these results. The plot is linear as predicted. The line in Figure 3 is the best fit for the experimental points from a linear regression computation and has a slope $r_{2}=1 \cdot 13$. The intercept at $1 / n=2.15$ is close to the theoretical $2 \cdot 00$. It is interesting to note that the equivalent limiting case $\left(r_{1}=0\right)$ of the classical binary equation predicts that $1 / n$ should vary linearly with $1 / x$ but that the intercept should be $1 \cdot 00$, and it is clear that this case does not fit the present results. 
GEORGE B. BUTLER

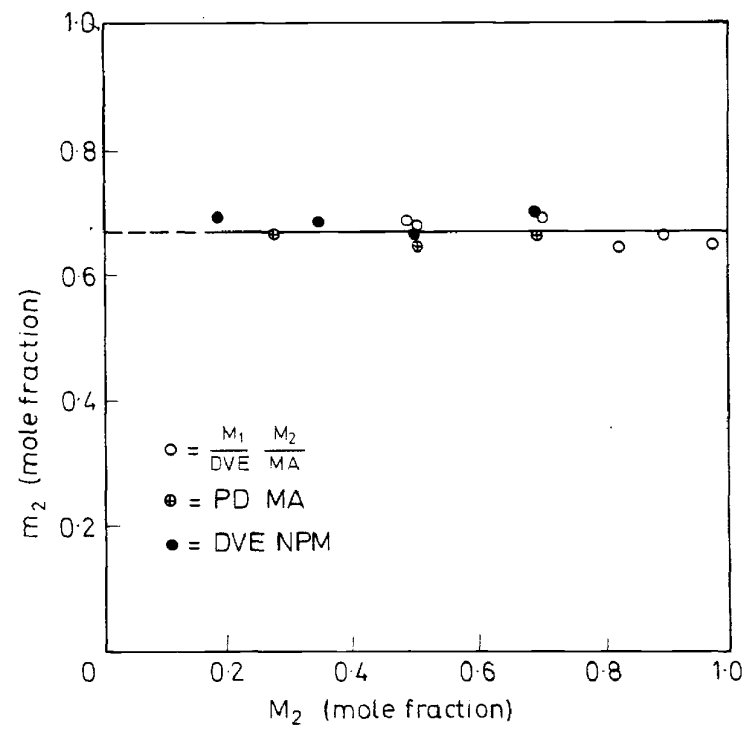

Figure 2. Copolymer composition vs. comonomer composition, 1,4-dienes $\left(\mathbf{M}_{1}\right)$ and alkenes $\left(\mathbf{M}_{2}\right)$. $($ DVE $=$ divinyl ether $; \mathrm{MA}=$ maleic anhydride $; \mathrm{PD}=1,4$-pentadiene $; \mathrm{NPM}=\mathrm{N}$-phenylmaleimide).

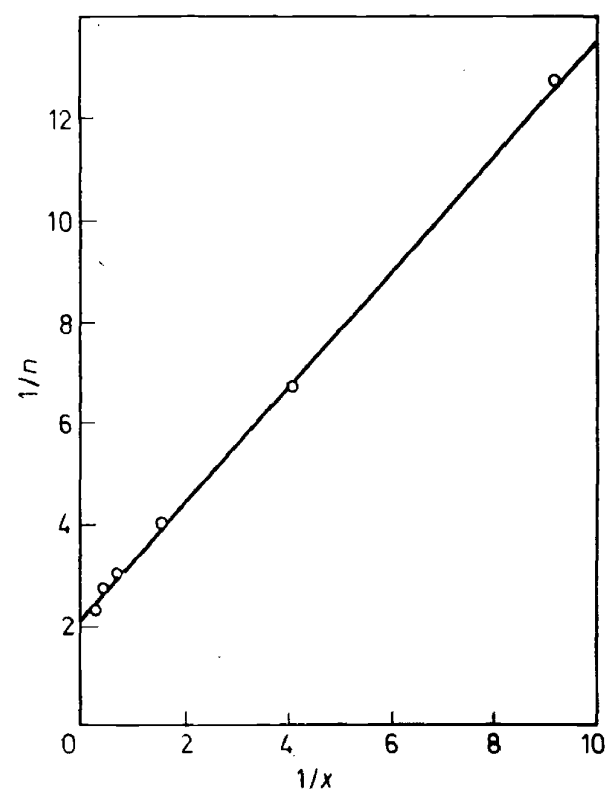

Figure 3. 1,4-Pentadiene $\left(\mathbf{M}_{1}\right)$-acrylonitrile $\left(\mathbf{M}_{2}\right)$ copolymers. $r_{2}=1 \cdot 129$. 
In all of the copolymerization systems considered above the proposed cyclic structure of the copolymers is supported by their solubility in dimethyl formamide, the absence of gelation even at high conversion under the conditions of these experiments, and the presence of little or no absorption in the infra-red at $6 \cdot 1 \mu$ for $\mathrm{C}=\mathrm{C}$. Further confirmation of the cyclic structure of the copolymers has been obtained.

The fact that our theoretical expressions in their respective limiting cases, when cyclization is predominant over linear propagation of the radicals $\mathrm{m}_{3}$, adequately describe the experimental data provides strong support for believing that the postulated mechanism of cyclopolymerization is essentially correct.

In a further test of the theory of Barton, Butler and Chapin ${ }^{11}$, Butler and Kasat $^{13}$ studied the cyclopolymerization of 3,3-dimethyl-1,4-pentadiene with acrylonitrile (Figure 4) and divinyl sulphone with acrylonitrile (Figure 5). The former system was found to be an example of Special Case (c) while the data from the latter experiments were found to fit that predicted by equation 14 or Special Case (a).

In Figure 4, it is shown that a plot of $1 / n$ vs. $1 / x$ is linear in this case, and to have the intercept at $1 / n=2$ as predicted theoretically. The line in Figure 4 is the best fit for the experimental points and has a slope of $r_{2}=3.31$.

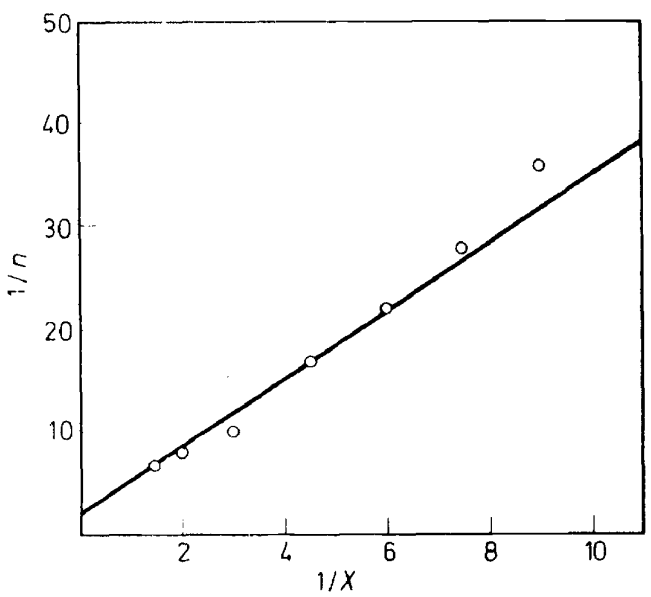

Figure 4. Copolymerization of 3,3-dimethyl-1,4-pentadiene and acrylonitrile. $r_{2}=3 \cdot 31$.

It was noted by these authors that the equivalent limiting case $\left(r_{1}=0\right)$ of the classical binary equation predicts that $1 / n$ should vary linearly with $1 / x$ but that the intercept should be 1.00 , making it apparent that this case does not fit their results.

The results of the copolymerization of divinyl sulphone with acrylonitrile are plotted in Figure 5. The excellent fit of the experimental results to equation 14 strongly supports the validity of the assumptions that $k_{\mathrm{c}} \gg k_{32}$ so that $a$ is very large and cyclization of radical $\mathrm{m}_{3} \cdot$ is very rapid. This is equivalent to considering the addition of monoolefin to diene radicals to 


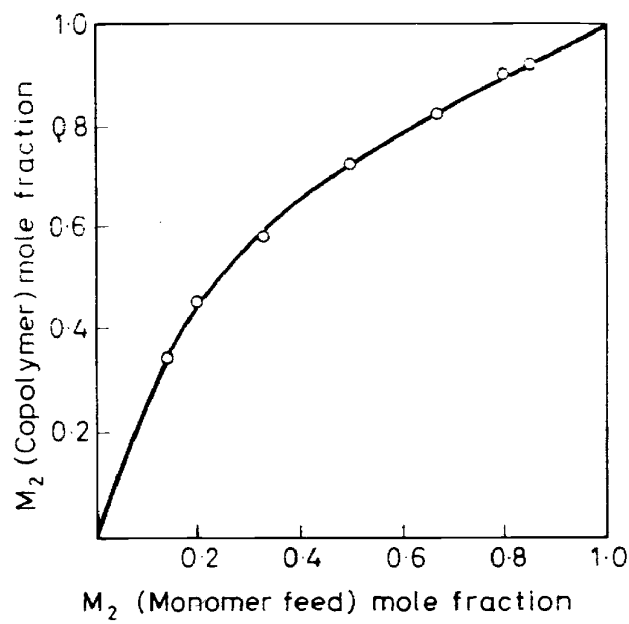

Figure 5. Copolymerization of divinyl sulphone $\left(\mathrm{M}_{1}\right)$ and acrylonitrile $\left(\mathrm{M}_{2}\right)(\bigcirc)$ experimental points; $(-)$ theory for $r_{1}=0.364, r_{2}=1.94 ; r_{c}=0.067$.

be a concerted bimolecular step proceeding through a cyclic transition state and producing the cyclic repeating unit.

In order to evaluate the monomer reactivity ratios of this system, $r_{\mathrm{c}}$ was assumed to be approximately equal to $r_{1}$ and was substituted for $r_{1}$ in equation 14. Plots of $r_{1}$ versus $r_{2}$ were then made. Each experiment with a given feed gives a curved line; the intersection of several of these allows the approximate evaluation of $r_{1}$ and $r_{2}$. Once these approximate values of $r_{1}$ and $r_{2}$ were obtained, to best fit the data for this system to equation 14 , a digital computer method, similar to that used by Tidwell and Mortimer ${ }^{12}$ for the classical binary copolymer composition equation, was used.

The solid line in Figure 5 is drawn for $r_{1}=0.364, r_{2}=1.94$ and $r_{\mathrm{c}}=0.067$. These are the values for which $\Sigma \Delta^{2}$, the sum of the squares of the difference between observed and computed values of $n$, was a minimum. These authors noted that a decrease in intrinsic viscosities of the copolymers as the mole fraction of divinyl sulphone increased was observed and offered as a possible, explanation the chain transfer property of divinyl sulphone. More recent work ${ }^{14}$ has shown that the bicyclic structural unit (16) is formed by homopolymerization of divinyl sulphone, and that although the relative rate of this homopolymerization is very low, at high divinyl sulphone ratios its formation is highly favoured.

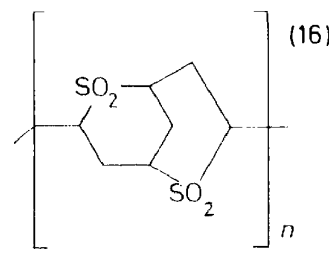


The copolymerizations of divinyl ether with fumaronitrile, tetracyanoethylene, and 4-vinylpyridine were studied by Butler, VanHaeren and Ramadier $^{15}$. Azobisisobutyronitrile was used as initiator in each case. The compositions of the copolymers were calculated from their nitrogen and unsaturation content. Over a wide range of initial monomer compositions, the mole fraction of fumaronitrile in the copolymers was found to be in the range $0.55-0.63$, and the copolymers contained only $2-3$ per cent unsaturation, indicating a high degree of cyclization. The composition of the copolymers of tetracyanoethylene indicated that cyclization occurred to only a small extent, perhaps due largely to steric factors, as the copolymers contained rather high unsaturation content. The values of $r_{1}=0.23$ and $r_{2}=0.12$ were obtained for this comonomer pair. The mole fraction of 4-vinylpyridine in the copolymers lies between 0.85 and 0.998 . If the assumption is made that $r_{1} \simeq r_{\mathrm{c}} \simeq 0$ and there is predominant cyclization, $r_{2}=32.0$ in this case. The difference in the composition of the copolymers is attributed to the difference between the electron density of the double bonds in the three comonomers.

\section{THE CHARGE TRANSFER CONCEPT}

The unusual and apparent general nature of this cyclocopolymerization in which bimolecular ring closure with the monoolefin even under otherwise unfavourable conditions, is highly favoured prompted Butler and Joyce ${ }^{16}$ to propose that the comonomer pair which leads to ring closure forms a charge-transfer complex prior to initiation, and that the propagating species is the complex rather than the individual comonomer molecules. This proposal was supported by the establishment of the existence of complexes in several comonomer pairs by use of ultraviolet spectrometry, and subsequent calculation of the equilibrium constants of formation of these complexes.

Kimbrough $^{17}$ has reported the alternating copolymerization of dihydropyran and maleic anhydride as shown below 17:

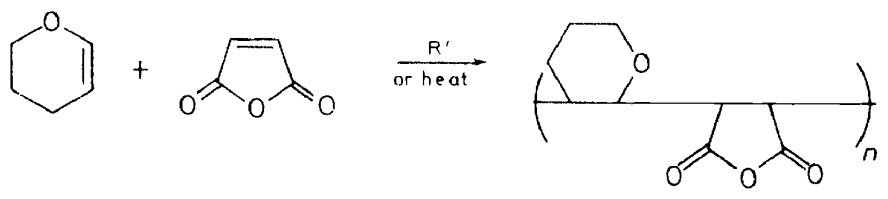

Since this structure was similar to the divinyl ether, maleic anhydride copolymer, a sample was prepared.

During the preparation of this sample, it was observed that a yellow colour was formed when maleic anhydride was added to either dihydropyran as a pure liquid or in a benzene solution. Even very dilute solutions showed this yellow colour. Since this colour diminished as the polymerization reached completion and since divinyl ether represents a structure similar in electronic nature to dihydropyran, research was begun to evaluate the nature of this colour. Vinyl ethers possess potential electron donor double bonds whereas maleic anhydride and similar structures possess electron acceptor double bonds. Double bond electron-density calculations ${ }^{18}$ 
substantiate the so-called $\pi$-electron acid-base character of this system which could well give rise to a charge transfer complex.

The characterization of charge transfer complexes is a well known procedure. Early work on charge transfer complexes was done by Benesi and Hildebrand ${ }^{19}$ on iodine/aromatic hydrocarbon complexes. Since this time a great deal of theoretical and experimental interest has been generated on these and other non-ionic complexes. Examples are complexes of $\mathrm{Br}_{2}$. $\mathrm{Cl}_{2}, \mathrm{ICl}, \mathrm{O}_{2}$. and $\mathrm{SO}_{2}$ with aromatic hydrocarbons. Also, maleic anhydridearomatic hydrocarbon complexes have been studied.

These complexes are characterized by an intense electronic absorption in the visible or near ultraviolet spectrum that is attributable to neither component of complex alone, but to a new molecular species, the complex itself. Mulliken ${ }^{20}$ considered such complexes to arise from a Lewis acid-base type interaction, the bond between the components of the complex arising from partial transfer of a $\pi$-electron from the $\pi$-base (aromatic molecule) to orbitals of the $\pi$-acids $\left(I_{2}\right.$, M.A., etc. $)$. The theory of charge-transfer complexes has recently been discussed by Kosower ${ }^{21}$.

Molecules capable of giving up an electron are defined as electron donors (D), and measurement of their ionization potentials provides a convenient index to donor ability. Molecules which can accept an electron are called acceptors (A), and acceptor ability is clearly related to electron affinity and reduction potential. There is a linear relationship between the energies of the charge-transfer bands of pyridinium iodides and the reduction potentials of pyridinium ions in acetonitriles.

Donors and acceptors interact, usually weakly, to form complexes (equation 18).

$$
\mathrm{D}+\mathrm{A} \stackrel{K_{e}}{=} \mathrm{D} . \mathrm{A}
$$

The complex absorbs light in a manner different from either $D$ or A such that an electron is transferred from $D$ to $A$ (equation 19). The theory of charge-transfer complexes suggests that the ground state is

$$
\mathrm{D}, \mathrm{A} \stackrel{h_{v}}{\rightarrow} \mathrm{D}^{+}, \mathrm{A}^{-}
$$

stabilized by some contribution (in resonance language) from the excited state, and that the light absorption process is more accurately described as in equation 20. The wave functions for the ground $(N)$ and excited $(E)$ states are given in equations 21 and 22.

$$
\begin{aligned}
\mathrm{D}, \mathrm{A}\left(\leftrightarrow \mathrm{D}^{+}, \mathrm{A}^{-}\right) \stackrel{h v}{\rightarrow} \mathrm{D}^{+}, \mathrm{A}^{-}(\leftrightarrow \mathrm{D}, \mathrm{A}) \\
\Psi N=a \psi_{0}(\mathrm{D}, \mathrm{A})+b \psi_{1}\left(\mathrm{D}^{+}, \mathrm{A}^{-}\right) \\
\Psi E=a \psi\left(\mathbf{D}^{+}, \mathrm{A}^{-}\right)-b^{*} \psi(\mathbf{D}, \mathrm{A})
\end{aligned}
$$

Stabilization of the ground state of a charge-transfer complex by a contribution from the charge-transferred form implies that, among other things, the complexing constant, $K_{\mathrm{c}}$, might be related to the donor and acceptor properties of the components of the complex.

The existence of the complex was deduced from the analysis of some change in the absorption spectrum of the mixture compared to the spectrum 
of the individual components. From a study of these changes as a function of the concentration of the components the values of the equilibrium constant $K$ and molar absorptivity $\varepsilon$ can be determined separately.

If the complex is assumed to be of a $1: 1$ ratio, then the association equilibrium may be written as follows (23):

$$
\begin{aligned}
& \text { (acceptor) (donor) (complex) } \\
& {[\text { M.A. }]+[\text { DHP] } \rightarrow[\text { MA:DHP }]}
\end{aligned}
$$

DHP $=$ dihydropyran; M.A. $=$ maleic anhydride

The equilibrium constant for complex formation then would be (24):

$$
K=\frac{[\text { complex }]}{\{[\text { acceptor }]-[\mathrm{C}]\}\{[\text { donor }]-[\mathrm{C}]\}}
$$

Simplifying by assuming [donor $] \gg[\mathrm{C}]$ which replaces $\{[$ donor $]-[\mathrm{C}]\}$ with [donor] gives equation 25.

$$
K=\frac{[\mathrm{C}]}{\{[\mathrm{A}]-[\mathrm{C}]\} \text { [donor }]}
$$

At the chosen ultraviolet absorption for the complex, [C] may be evaluated from the expression $d=[\mathrm{C}] \varepsilon_{\mathrm{c}} l$ where $d$ is the maximum optical density. $\varepsilon_{\mathrm{c}}$ is the molar extinction coefficient of the complex and $l$ is the path length in centimeters. Solving for $[\mathrm{C}]$, substitution and rearrangement gives the following (26):

$$
\frac{\text { [acceptor }] l}{d}=\frac{1}{K \varepsilon[\text { donor }]}+\frac{1}{\varepsilon} .
$$

When this expression is multiplied by the [donor], one arrives at an equation known as the Scott Equation ${ }^{22}(27)$ :

$$
\frac{\text { [donor] [acceptor] } l}{d}=\frac{1}{K \varepsilon}+\frac{1}{\varepsilon} \text { [donor]. }
$$

These arrangements are made with the assumption that [donor] $\gg$ [acceptor]. The equation can be modified for both $[A] \geqslant[D]$ and $[A] \cong[D]$.

It should be noted that the criterion for existence of a complex is not the appearance of a new (or shifted) absorption band, but rather that the new absorption can be analyzed by one of the procedures above to give a single. non-zero, value for $K$ and a finite, constant value for $\varepsilon$. Reliable equilibrium constants are obtained only when equilibrium concentration of the complex is of the same order of magnitude as the equilibrium concentration of the most dilute component ${ }^{22}$. This means that almost all of the acceptor is complexed by donor in these experiments.

In Table 1 is a summary of equilibrium constants and molar extinction coefficients for various complexes. It should be mentioned that although these values of $K$ are low compared to other well known complexes, they are real. The solution molarity of donor and acceptor was regulated to fall within Person's criteria ${ }^{23}$. Maximum donor concentration in these solutions was between the limits of 0.1 and $9 \cdot 0$ times the value of $1 / K^{23}$. 
GEORGE B. BUTLER

Table 1. Equilibrium constants and molar extinction coefficients for various complexes

\begin{tabular}{c|c|c|c}
\hline Complex & \multicolumn{1}{|c|}{$K$} & $\varepsilon_{\mathrm{c}}$ & $\lambda_{\max } \mathrm{m}_{\mu}$ \\
\hline $\mathrm{DVE}^{a}: \mathrm{MA}^{b}$ & 0.0137 & 2745 & 275 \\
DVE $^{c}: \mathrm{MI}^{\mathbf{c}}$ & $0 \cdot(1374$ & $379 \cdot 2^{d}$ & $d$ \\
$\mathrm{DHP}^{\prime}: \mathrm{MA}^{j}$ & $0 \cdot 02$ & $?$ & 295 \\
$\mathrm{DVE}^{\prime}: \mathrm{FN}^{j}$ & 0.0151 & 7794 & 265 \\
\hline
\end{tabular}

"Divinyl ether

"Maleic anhydride.

- Maleimide.

"An average of absorbance values at 260,270 , and $280 \mathrm{~m} \mu$ was used since the maximum appears to be obscured by the DVE absorption below $260 \mathrm{~m} \mu$. Absolute $\varepsilon$ may be in doubt.

Dihydropyran.

i Fumaronitrile.

Because of the nature of copolymerization products resulting from mixtures of the above mentioned monomers which show charge transfer characteristics, one is led to consider the possibility that the complex is involved as a reactive intermediate in the polymerization mechanism. Dihydropyran and maleic anhydride give a perfect $1: 1$ copolymer as shown by Kimbrough and confirmed by this laboratory. Alternation, in this case, could well be explained by reaction of a charge transfer complex with the propagating free radical (28):

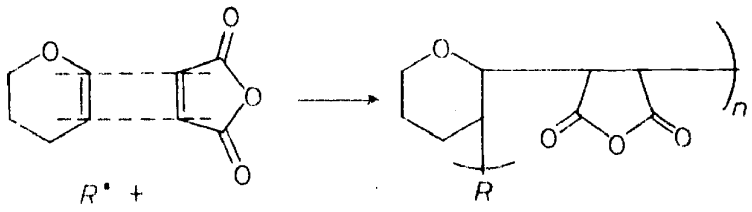

In a similar manner polymerization of a $1: 1$ complex of divinyl ether and maleic anhydride could explain the novel formation of cyclic copolymer discovered by Butler ${ }^{6}$. as shown in equations 29 or 30 .

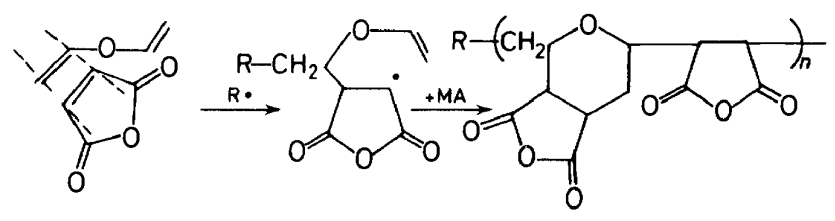<smiles>[R]CC1OCCC2C(=O)OC(=O)C12</smiles>

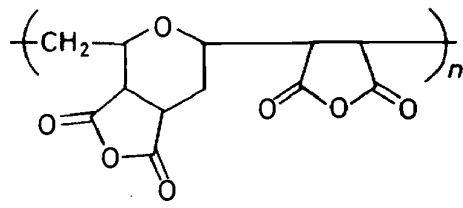




\section{COPOLYMERIZATION MECHANISM}

Since the initial derivation of a suitable copolymer composition equation by Barton, Butler and Chapin ${ }^{11}$, kinetic data for numerous combinations of monomers have been determined. In all cases very high values for $a$ have resulted ( $a$ is the ratio of the relative rates of cyclization and addition to another monoolefin). This high value is remarkable in the case of monomers such as acrylonitrile, and indicates that almost all the radicals in position to form a ring prefer to do so.

The results of this research suggested a reaction involving a chargetransfer complex. The geometry of this complex is unknown. but a $1: 1$ stoichiometry limits the number of possible structures.

One possible complex in the system of divinyl ether and maleic anhydride has only one double bond in the ether complexed as shown in the preceding illustrated scheme 29. It should be noted that the intermediate radical represents a situation completely analogous to the ring-closing propagation step in the 1,6-diene inter-intramolecular mechanism, previously described by Butler and Angelo $^{3}$ (31).

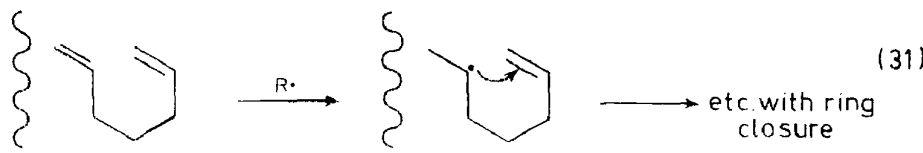

Mulliken ${ }^{20}$ determined the geometry of organic charge-transfer complexes simply by producing the structure that gives the maximum $\pi$-orbital overlap for the donor and acceptor. A complex formed from one double bond of divinyl ether and maleic anhydride is geometrically sound.

When coupled with the kinetic data, which show extremely rapid ring closure, another reaction scheme, which also involves reaction of a chargetransfer complex of different geometry, seems attractive; this is shown in equation 30 .

Orientation of monomers, via a charge-transfer complex prior to freeradical reaction, explains this unusual cyclic structure and also accommoda tes the kinetic data. A random reaction of monomers in this polymerization is totally eliminated on the basis of all analytical data that has been presented. The probability that these monomers in the absence of charge-transfer participation will obtain the correct orientation in solution to give the product can be assumed to be very low, simply by inspection.

The reaction of a charge-transfer complex with a propagating free radical to produce a linear polymer with cyclic units, offers the best explanation of the formation of this polymer. On the basis of evidence currently a vailable this is the most reasonable pathway for the reaction to follow. Identification of a charge-transfer complex, however, in a reaction system does not necessarily mean that it is on the reaction coordinate, although many proposals of this kind have been made.

In an attempt to explain the alternating copolymer of styrene and maleic anhydride Bartlett and Nozaki ${ }^{24}$ analyzed a charge-transfer complex which, they claimed was the reactive intermediate. This work was later supported by Barb ${ }^{25}$. Complexes of a series of substituted styrenes and maleic anhydride 
and their corresponding alternating copolymers were studied by Walling et $a l^{26}$. These researchers concluded that the complex was determining the nature of the polymeric product of a free-radical initiation.

In other fields analogous work lends support to this theory. Robson et al. ${ }^{27}$ have studied photochemical reactions in which appropriate filters have been used to exclude all reactions except those of charge-transfer complexes. The systems studied are not unlike those at hand: cyclohexene, the maleate and fumarate esters, and maleic anhydride. These yield cyclo addition products when photoexcited. In all cases, when a charge-transfer complex has been identified, the stereochemistry of these reactions is much more specific than otherwise.

In the field of polymer chemistry the authors of a recent publication ${ }^{28}$ arrived independently at a conclusion that was similar to the conclusior arrived at in this laboratory. They concluded that in the system of $p$-dioxen 6 and maleic anhydride the limiting factor was the reaction of the chargetransfer complex. This complex was identified spectrophotometrically. Evidence of the inclusion of the charge-transfer complex in the reaction comes from both the alternating copolymerization of $p$-dioxene and maleic anhydride and the unique idea of a terpolymerization of acrylonitrile, $p$-dioxene, and maleic anhydride. The terpolymerization still yielded a 1:1 ratio of $p$-dioxene and maleic anhydride; normal terpolymerization kinetics would not yield this $1: 1$ ratio.

More recent work by these authors ${ }^{29}$ has led to the conclusion that the alternating copolymerization can be reduced to a homopolymerization of the charge-transfer complex formed between the comonomers and that the terpolymerization of these alternating copolymerizable monomers with a third monomer which has little or no interaction with either monomer of the pair can be reduced to a copolymerization of the charge-transfer complex between the alternating copolymerizable monomers and the third monomer.

\section{ROLE OF CHARGE-TRANSFER COMPLEX}

In order to provide further evidence for the formation of a charge-transfer complex the comonomers of a cyclocopolymerizable pair and its participation in the copolymerization, Butler and Campus ${ }^{30}$ undertook both a copolymerization study of a suitable comonomer pair and a terpolymerization study of this comonomer pair with a third monomer.

The 1,4-diene used was divinyl ether (DVE) and the monoolefins were maleic anhydride (MA) and fumaronitrile (FN). Acrylonitrile (AN) was used as the third monomer in the terpolymerization experiments. For comparison, the results of a complex study of styrene-maleic anhydride and ethyl vinyl ether (EVE)-maleic anhydride are also reported.

\section{Determination of the stoichiometric composition and the equilibrium constant of complexation of different charge-transfer complexes formed between comonomers which undergo cyclocopolymerization}

Stoichiometric Composition-When a solution of maleic anhydride (or fumaronitrile) in chloroform (or DMF) is added to a solution of a 1,4-diene (DVE) or ethyl vinyl ether (EVE) in the same solvent there appears in the 
ultra violet (UV) spectrum of the mixture a new and broad band whose appearance and position can be attributed to the formation of electrondonor-acceptor (E.D.A.) complexes. The interpretation of the spectra of these complexes permits the determination of their stoichiometric composition using the continuous variation method ${ }^{31,32}$. The results are shown in Figure 6.

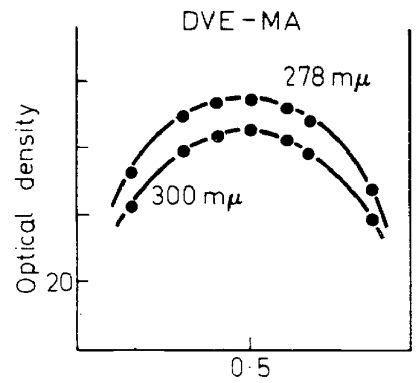

Volume fraction of $M A(x)$ solvent: $\mathrm{CHCl}_{3}$

EVE-MA

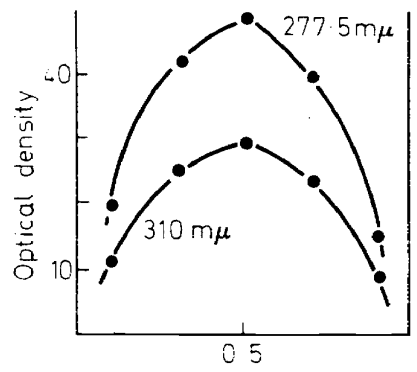

Volume fraction of MA $(x)$ solvent $\mathrm{CHCl}_{3}$

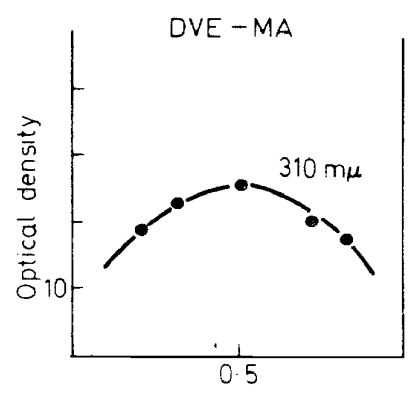

volume fraction of MA : $x$; solvent DMF

DVE - FN

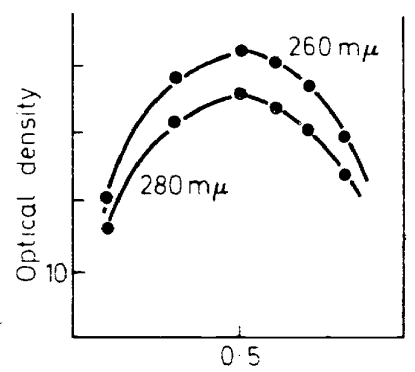

Volume fraction of $F N(x)$ solvent $\mathrm{CHCl}_{3}$

Figure 6. U.V. determination of the composition of the charge-transfer complexes.

Since MA or FN absorbs near the maximum absorption of their complexes, the experiments had to be run with an identical molar solution of acceptor in the reference beam. The charge-transfer band maximum is at $278 \mathrm{~m} \mu$ for the DVE:MA complex, and at $20 \mathrm{~m} \mu$ for the DVE:FN complex. In the case of EVE:MA, the maximum is observed at $277.5 \mathrm{m \mu}$. In all the cases, the maximum absorbance is found to be for a molar fraction of 0.5 in acceptor; hence it can be concluded that the stoichiometry of the complexes DVE-MA (in $\mathrm{CHCl}_{3}$ and DMF), DVE-FN and EVE-MA is $1: 1$. Also reported is the $1: 1$ complex formation of trimethyl vinyl silane $\left(\mathrm{Me}_{3} \mathrm{VinSi}\right)$ and dimethyl divinyl silane $\left(\mathrm{Me}_{2} \mathrm{Vin}{ }_{2} \mathrm{Si}\right)$ with maleic anhydride as acceptor, together with their radical copolymerization. As for the oxygen and the carbon series, the silicon series gives an alternating 1:1 copolymer in the case of $\mathrm{Me}_{3} \mathrm{VinSi}-$ 
MA and 1:2 cyclocopolymer in the case of $\mathrm{Me}_{2} \mathrm{Vin}_{2} \mathrm{Si}-\mathrm{MA}$. The geometry of these complexes is unknown as well as whether one or both double bonds of the diene are involved in the complex.

Some observations were reported which could be of interest in the understanding of the structure of the complex. It was reported ${ }^{33}$ that alkyl vinyl ethers as well as other electron-rich alkenes react with tetracyanoethylene (TCNE) in order to give a 1:1 addition product having a 1,1,2,2-tetracyanocyclobutane structure. While the reaction of ethyl vinyl ether (EVE) with TCNE is very fast, the reaction of DVE-TCNE is much slower and only the $1: 1$ addition product could be isolated. The structure of the DVE-TCNE adduct was determined by NMR to be as follows (32):<smiles>C=COC1CC(C#N)(C#N)C1(C#N)C#N</smiles>

This structure is analogous to the structure of the adduct of EVE-TCNE, without the second olefinic bond being involved; the remaining double bond of the DVE-TCNE adduct does not react with an additional amount of TCNE. Moreover, the e value given ${ }^{34}$ for $\operatorname{EVE}(\mathrm{e}=-1.6)$ is greater than that observed in the case of DVE $(e=-1 \cdot 3)$. Such observations lead to the conclusion that the electron density of the double bond is greater for EVE than for DVE, which is easily explained by the effect of the ethoxy group.

On the other hand, in the charge-transfer complex theory it is well known ${ }^{35}$ that, when different donors interact with the same acceptor, the chargetransfer energy varies linearly with the ionization potential of the donors and since the ionization potential for alkene derivatives is directly related to the electron density of the double bond, it is reasonable to expect that the complex of DVE-MA will not absorb at a significantly longer wave length than the complex of EVE-MA. The results are given in Table 2.

Table 2. Maximum absorbtion ${ }^{a}$ of the charge-transfer complexes between vinyl ethers and maleic anhydride

\begin{tabular}{l|l}
\hline \multicolumn{1}{c|}{ Complex } & \multicolumn{1}{c}{ Max. } \\
\hline EVE-MA & \multicolumn{1}{c}{$277.5 \mathrm{m \mu}$} \\
DVE-MA & $278 \mathrm{m \mu}$ \\
Furan-MA & $291 \mathrm{~m} \mu$ \\
\hline
\end{tabular}

a solvent: $\mathrm{CHCl}_{3}$.

These observations show that the maximum absorption of the DVE-MA complex compared with the EVE-MA complex is not found at a significantly longer wave length, which suggests that the DVE-MA complex must have some other configuration than that of the EVE-MA complex and that 
presence of both double bonds would have some effect on the chargetransfer interaction. Since the cyclic structure is known to appear in the copolymer, it is highly probably that the donor (DVE) in the complex has a pseudo-cyclic structure, analogous to the furan molecule. As shown in Table 2, the furan-MA complex has its maximum at $291 \mathrm{~m} \mu$, a longer wave length than the non-cyclic ethers. These observations do not establish the absolute configuration of the complex, but since all of them substantiate each other, it can reasonably be postulated at the present time that both double bonds of DVE participate in complex formation with maleic anhydride in a more or less pseudo-cyclic form similar to the furan structure.

Determination of the equilibrium constant of complexation-It is known that it is possible to determine the equilibrium constant of charge-transfer complexes either by UV spectroscopy using the Benesi-Hildebrand equation $^{19}$ or by nuclear magnetic resonance as was reported in the literature recently ${ }^{36,37}$. The NMR method, where it is applicable, is more accurate and easier, since in the case of weak complexes the UV absorption maximum is often near that of one of the components. In all the cases the shift of the acceptor protons (singlet) was followed; the concentration of the acceptor was kept constant while the concentration of the donor was increased; the donor is always in large excess compared to the acceptor. The equation given by Hanna and Ashbaugh ${ }^{36}$ was used (33):

$$
\frac{1}{\Delta_{\mathrm{obsd}}^{A}}=\frac{1}{Q \Delta_{A D}^{A}} \frac{1}{\xi D}+\frac{1}{\Delta_{A D}^{A}}
$$

Where: $-\Delta_{A D}^{A}=\delta_{\mathrm{obsd}}^{A}-\delta_{O}^{A}$ is the difference between the shift of the acceptor protons in complexing media ( $\delta_{\text {obsd }}^{A}$ ) and the shift of the acceptor in uncomplexed form $\left(\delta_{O}^{A}\right)$;

$-\Delta_{A D}^{A}=\delta_{A D}^{A}-\delta_{O}^{A}$ is the difference in the shift of the acceptor protons in pure complex ;

$-\xi_{D}$ is the concentration of the donor which has always to be much greater than the acceptor concentration in order that $Q=K$, the equilibrium constant of complexation and that the quotient $\gamma_{A D} / \gamma_{A} \gamma_{D}$ remains constant over the range of solutions studied.

In these experiments the acceptor concentration was kept constant at $0.05 \mathrm{M}^{-1}$, while the donor concentration was increased from 0.3 to $9 \mathrm{M}^{-1}$. By plotting $1 / \Delta_{\text {obsd }}^{A}$ as a function of $1 / \xi_{D}$, in every case, a straight line was obtained; the slope of the line and its intersection with the ordinate permit a first approximation of the equilibrium constant of complexation and of the shift of acceptor protons in the pure complex. For comparative purposes, the equilibrium constant of the complex styrene-maleic anhydride was also determined by this method (Figure 7).

For a more exact determination of $K$ and $\Delta_{A D}^{A}$, the method of least squares was applied to the equation, and the following results were obtained (Table 3 ).

As expected, the values of $K$ are relatively low; however they are real; 
for comparison, the value reported by Foster and $\mathrm{Fyfe}^{37}$ for the complex between benzene and trinitrobenzene in $\mathrm{CCl}_{4}$ at $35 \cdot 5^{\circ}$ is $0.31 \mathrm{~lm}^{-1}$.

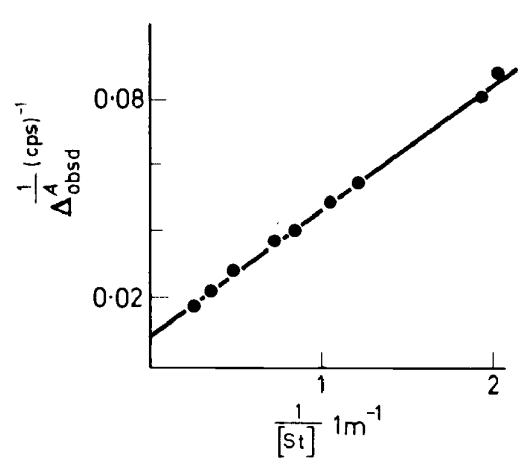

Styrene-Maleic anhydride $T=38^{\circ}$, solvent $\mathrm{CCl}_{4}$

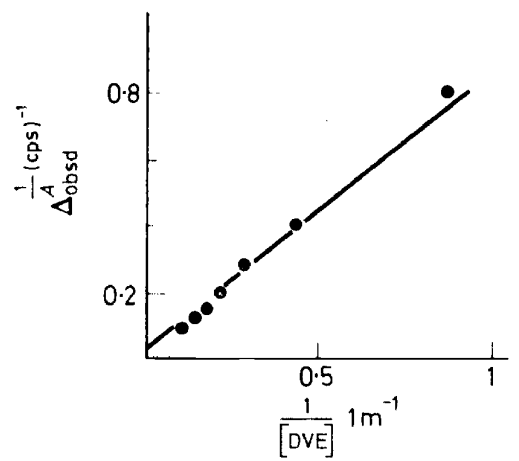

Divinyl ether-Maleic anhydride $T=24^{\circ}$, solvent $\mathrm{CDCl}_{3}$

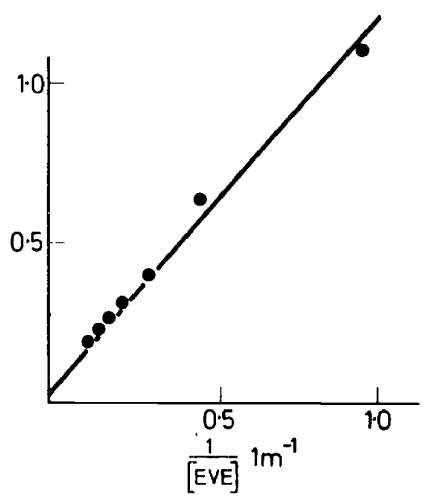

Ethyl vinyl ether-Maleic anhydride $r=26^{\circ}$, solvent $\mathrm{CDCl}_{3}$

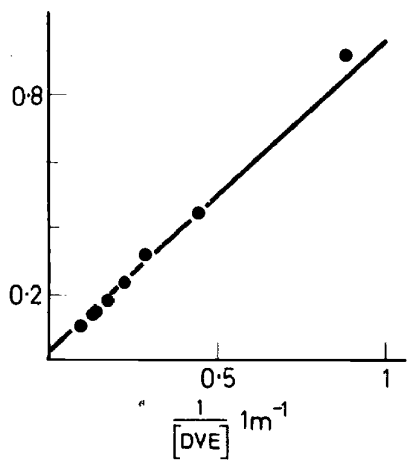

Divinyl ether-Fumaronitrile $T=24^{\circ}$, solvent $\mathrm{CDCl}_{3}$

Figure 7. N.M.R. determination of the equilibrium constant of complexation of the chargetransfer complexes.

Table 3. NMR determination of the equilibrium constants of chargetransfer complexes

\begin{tabular}{l|l|c|r|c}
\hline \multicolumn{1}{c|}{ Complex } & Solvent & Temperature ${ }^{\circ} \mathrm{C}$ & $\Delta_{A D}^{A} \mathrm{cps}$ & $K$ in $\mathbf{l m}^{-1}$ \\
\hline ST:MA & $\mathrm{CCl}_{4}$ & 38 & $125 \cdot 0$ & 0.216 \\
EVE:MA & $\mathrm{CDCl}_{3}$ & 24 & $21 \cdot 3$ & 0.041 \\
DVE:MA & $\mathrm{CDCl}_{3}$ & 24 & $33 \cdot 5$ & 0.036 \\
DVE:FN & $\mathrm{CDCl}_{3}$ & 24 & $127 \cdot 5$ & 0.008 \\
\hline
\end{tabular}




\section{Dilution effect on the copolymerization of divinyl ether with fumaronitrile}

Some authors ${ }^{26}$, in the case of alternating free-radical copolymerization, opposed the postulate of participation of the molecular complex in the mechanism of reaction because of the absence of a dilution effect on the monomer reactivities. If we represent by $A$, the acceptor concentration, by $D$ the donor concentration and by $K$, the equilibrium constant of formation of the molecular complex $C$, one can write the reaction for formation of this complex as follows (34):

$$
A+D \stackrel{K}{\rightleftharpoons} C
$$

the complex concentration being (35):

$$
[C]=K[A][D]
$$

By diluting the reaction solution by a factor of two, the concentration of the complex in the new medium will be decreased by a factor of four (36):

$$
[C]^{\prime}=K\left[\frac{A}{2}\right]\left[\frac{D}{2}\right]=\frac{[C]}{4}
$$

If the molecular complex is responsible to some extent for the regularity of the $1: 2$ structure in the cyclopolymer, it is quite reasonable to expect a decrease of this regularity by dilution, since the dilution will decrease the relative concentration of the complex.

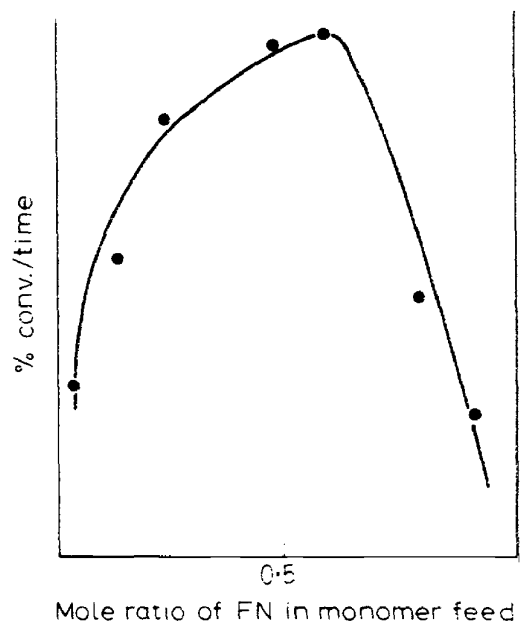

Figure 8. Rate of copolymerization of DVE-FN ${ }^{15}$.

The copolymerization of divinyl ether with fumaronitrile has been reported from this laboratory ${ }^{15}$. While in alternating copolymerization, a maximum in the rate of polymerization for an initial monomer feed of $1: 1^{28}$ (medium in which the concentration of complex is highest) is observed, in this case (Figure 8) a polymerization rate maximum for a monomer feed of DVE:FN equal to $1: 2$, similar to the composition of the polymer obtained, is observed; 
recall however, that the stoichiometry of the complex is $1: 1$. The two steps of cyclocopolymerization, namely the formation of the cyclic radical and the addition of the electron poor monomer to this cyclic radical, seem thus to be dependent upon the electronegativity difference between the two monomers, which is responsible for the complex formation. Using the optimal monomer feed for DVE:FN of 1:2, copolymerizations were carried out for different total concentrations in the same solvent (DMF), in order to determine whether there was a dilution effect in this system. The results are given in Table 4 and Figure 9.

Table 4. Dilution effect on the copolymerization ${ }^{a}$ of divinyl ether $\left(M_{1}\right)$ with fumaronitrile $\left(M_{2}\right)$

\begin{tabular}{l|c|c|c|c}
\hline Run No. & $\begin{array}{c}\text { Total } \\
\text { Concentration } \\
\text { in } \mathrm{ml}^{-1}\end{array}$ & $\% N^{\mathrm{h}}$ & $M_{2}$ & {$[\eta] \mathrm{dl} / g^{c}$} \\
\hline CD11 & 6 & $24 \cdot 74$ & $0 \cdot 660$ & \\
CD16 & $4 \cdot 5$ & $24 \cdot 00$ & $0 \cdot 642$ & $0 \cdot 13$ \\
CD13 & 3 & $23 \cdot 68$ & $0 \cdot 630$ & $0 \cdot 11$ \\
CD12 & $1 \cdot 5$ & 23.05 & $0 \cdot 615$ & \\
CD15 & 0.5 & $22 \cdot 66$ & $0 \cdot 600$ & \\
\hline
\end{tabular}

${ }^{a}$ solvent $=\mathrm{DMF} ; T=60^{\circ} ;$ ratio DVE $: \mathrm{FN}=1: 2 ;$ initiator $=$ AIBN $(1 \mathrm{~mole} \%)$.

${ }^{b}$ Nitrogen percentage was corrected on the basis of $95 \%$ found for polyacrylonitrile.

${ }^{c} 30^{\circ}$, acetone.

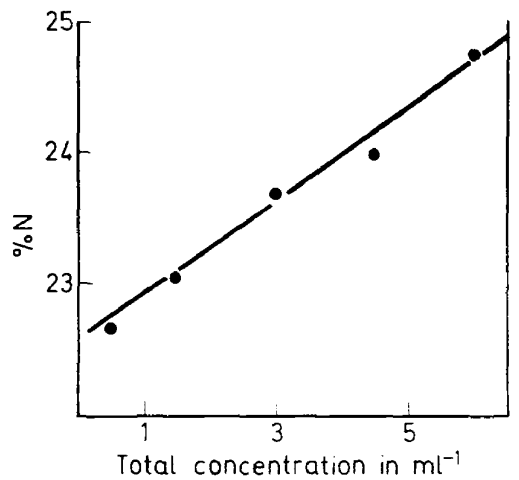

Figure 9. Dilution effect on the copolymerization of divinyl ether $\left(M_{1}\right)$ with fumaronitrile $\left(\mathbf{M}_{2}\right)$.

Upon diluting the medium of copolymerization, not only a decrease of the rate of polymerization as expected was observed, but also a decrease in the nitrogen content of the copolymer, and consequently in the fumaronitrile content was observed. The upper limit of FN content in the copolymer corresponds thus to the $1: 2$ structure 37 previously described $^{15}$ : 


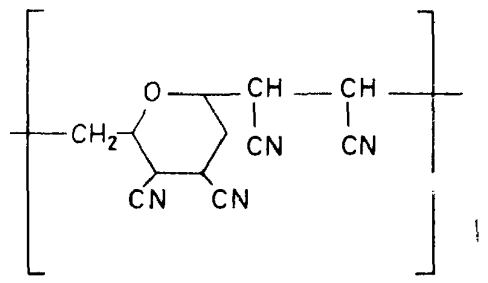

Since by dilution, the nitrogen content decreases, this $1: 2$ regularity of the copolymer must also decrease. NMR and IR studies however do not show any detectable change in the spectra of the copolymers and particularly in their unsaturation content; such structure as 38 must thus be unimportant.<smiles>C=COC(CC)C(C)C(C)C</smiles>

Two remaining possibilities which can explain the decrease of $\mathrm{FN}$ in the copolymer are (a) the decrease of selectivity of addition to the cyclic radical and (b) homopolymerization of a limited number of divinyl ether units. Both require addition of vinyl ether radicals to vinyl ether double bonds. This has been shown to occur in a homopolymerization study of DVE ${ }^{38}$; however the rate of this homopolymerization has been shown to be very low compared to its copolymerization with FN, but in the absence of sufficient $F N$ this alternative course would be favoured. The first possibility would lead to a limited sequence of structure 39 units:

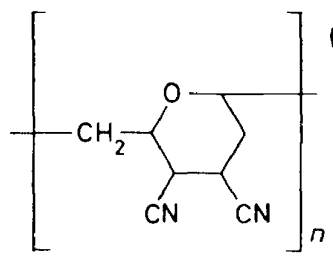

The second possibility would lead to a limited sequence of structure 40 units $^{38}$ :<smiles>CC(C)(C)CC1CC2CC(CC(C(C)(C)C(C)(C)O)O2)O1</smiles>

The structure of the copolymer can thus be represented as $[37]_{\mathrm{x}}-[39]_{\mathrm{y}}-$ $[40]_{z}$ - in which $\left.\left.x\right\rangle \geqslant\right\rangle y, z$. Consequently, it can be concluded that addition to the cyclic radical is less selective than the cyclization step. An analogous effect has also been observed in the case of terpolymerization. 
Radical terpolymerization of divinyl ether, maleic anhydride and acrylonitrile

The copolymerizations of DVE:MA and DVE:AN were reported earlier by this laboratory ${ }^{7,8}$. While the copolymer DVE:MA has a true 1:2 structure, the copolymer DVE:AN is generally richer in acrylonitrile than the $1: 2$ composition expected ; however, in this case also, the divinyl ether enters into the copolymer in a six-member ring form by copolymerization with AN. The high concentration in AN in the copolymer can be explained by the fact that AN can readily homopolymerize by a free radical mechanism while MA does not.

Another explanation could be found in the fact that the polymerizable double bond of acrylonitrile is less electron deficient $(e=1.20)^{39}$ compared with the values of maleic anhydride $(e=2 \cdot 25)$ and fumaronitrile $(e=1.96)$; the molecular association between AN and DVE will thus be much less stable than the association of DVE-MA and thus the effect of this association on the polymerization mechanism, if any, will be greater in the case of MA and FN than in the case of AN. We were indeed unable to detect any obvious molecular association between DVE and AN, while we showed in the first part that DVE and MA form a stable charge-transfer complex. On the other hand, acrylonitrile $\left(\mathbf{M}_{1}\right)$ copolymerizes only to a small extent, if at all, with maleic anhydride $\left(\mathrm{M}_{2}\right)$. The values of the reactivity ratios given in the literature $\operatorname{are}^{40} r_{1}=6, r_{2}=0\left(T=60^{\circ} \mathrm{C}\right)$.

In the first series of experiments the donor-acceptor ratio was kept constant at the optimal value of $1: 2$, the donor being divinyl ether, and the acceptor being the sum of maleic anhydride and acrylonitrile; in every experiment the relative molar concentration in MA and AN was varied, their sum being always twice the molar concentration of DVE. In a second series of experiments different ratios of DVE:MA:AN, were used, the total concentration being the same in all the experiments and equal to 6 moles per litre. The results are given in Table 5 and Figure 10.

Table 5. Terpolymerization ${ }^{a}$ of divinyl ether-maleic anhydride-acrylonitrile

\begin{tabular}{|c|c|c|c|c|c|c|c|}
\hline \multirow[t]{2}{*}{ Run No. } & \multicolumn{3}{|c|}{ Monomer Composition in $\%$} & \multirow[t]{2}{*}{ Conversion in $\%$} & \multicolumn{3}{|c|}{ Polymer Composition ${ }^{h}$ in $\%$} \\
\hline & $\mathrm{AN}$ & MA & DVE & & AN & MA & DVE \\
\hline T II 3RE & $6 \cdot 6$ & $60-0$ & $33 \cdot 3$ & $6 \cdot 32$ & $6 \cdot 6$ & $60-8$ & $32 \cdot 6$ \\
\hline T II IR3 & $13 \cdot 3$ & $53 \cdot 3$ & $33 \cdot 3$ & $3 \cdot 24$ & $13 \cdot 9$ & $53 \cdot 9$ & $32 \cdot 1$ \\
\hline T II 4 RE & $20 \cdot 0$ & $46 \cdot 6$ & $33 \cdot 3$ & $6 \cdot 54$ & $15 \cdot 2$ & $53 \cdot 5$ & $31 \cdot 2$ \\
\hline T II $5 \mathrm{RE}$ & $33 \cdot 3$ & $33 \cdot 3$ & $33 \cdot 3$ & $7 \cdot 50$ & $27 \cdot 2$ & $43 \cdot 6$ & $29 \cdot 2$ \\
\hline T II 2R3 & $40 \cdot 0$ & 266 & $33: 3$ & $3 \cdot 29$ & $35 \cdot 7$ & $36 \cdot 9$ & $27 \cdot 4$ \\
\hline T II 6 & $50 \cdot 0$ & $16 \cdot 6$ & $33 \cdot 3$ & $4 \cdot 22$ & $45 \cdot 2$ & $31 \cdot 3$ & $23 \cdot 7$ \\
\hline T II 7B & $10 \cdot 0$ & $10 \cdot 0$ & $80 \cdot 0$ & $9 \cdot 37$ & $22 \cdot 0$ & $48 \cdot 6$ & $29 \cdot 4$ \\
\hline T II 8 & $10 \cdot 0$ & $30 \cdot 0$ & $60 \cdot 0$ & $8 \cdot 42$ & $16 \cdot 6$ & $55 \cdot 8$ & $27 \cdot 6$ \\
\hline T II 9 & $25 \cdot 0$ & $15 \cdot 0$ & $60 \cdot 0$ & 4.90 & $30 \cdot 5$ & $45 \cdot 1$ & $24 \cdot 3$ \\
\hline T II 10 & $15 \cdot 0$ & $70 \cdot 0$ & $15 \cdot 0$ & $2 \cdot 64$ & $12 \cdot 3$ & $55 \cdot 6$ & $32 \cdot 1$ \\
\hline T II 11 & $30 \cdot 0$ & $60 \cdot 0$ & $10 \cdot 0$ & $2 \cdot 16$ & $29 \cdot 8$ & $43 \cdot 7$ & $26 \cdot 5$ \\
\hline
\end{tabular}

a solvent: DMF; $T=60 \mathrm{C}$; initiator $=\mathrm{AIBN}: 1$ mole $\% ;$ total initial monomer concentration $=6$ moles $/ 1$.

Based upon percentage of nitrogen and carboxylic content.

$30 \mathrm{C}, \mathrm{DMF}$ 

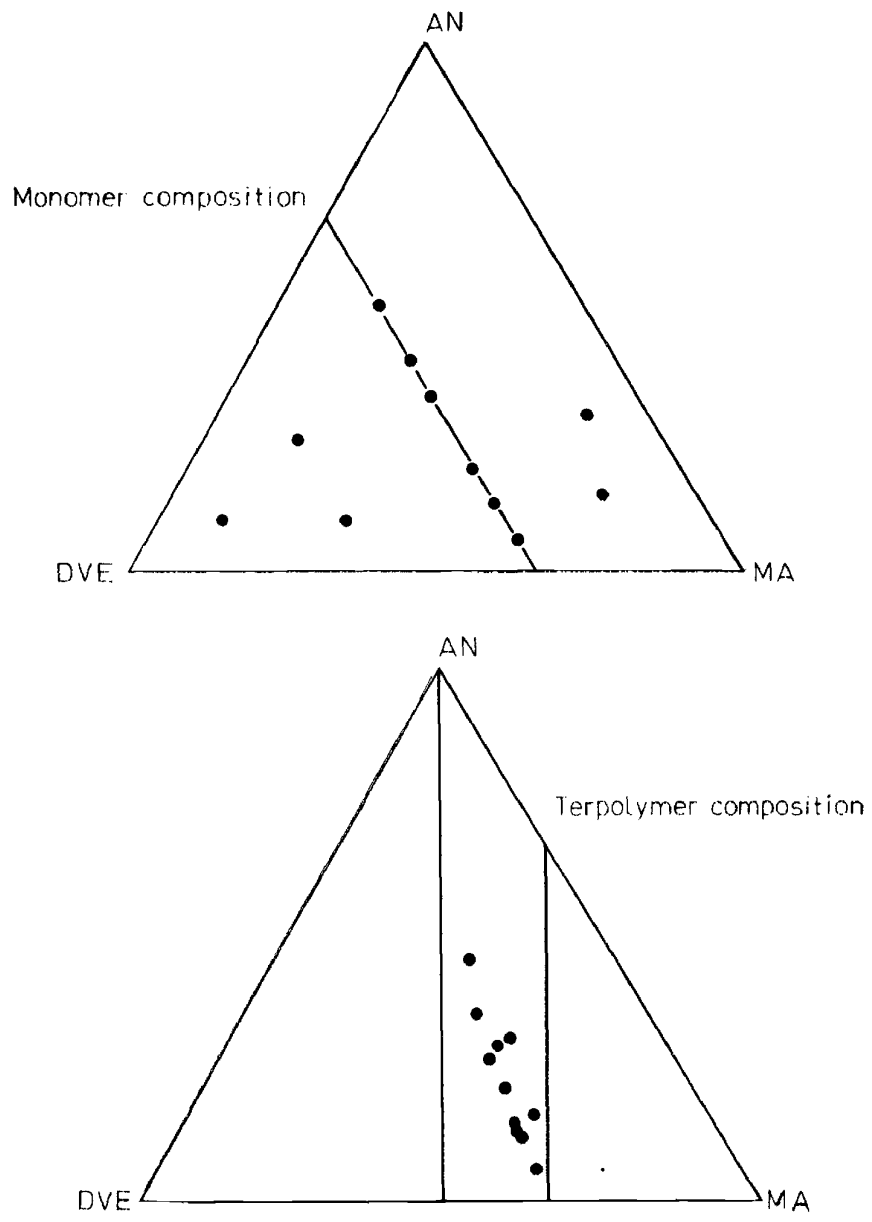

Figure 10. Radical terpolymerization of divinyl ether (DVE) maleic anhydride (MA)-acrylonitrile (AN).

From these experiments, it was observed that when the ratio donor: acceptor was kept constant $(1: 2)$, while varying the relative concentration in MA and $\mathrm{AN}$, a terpolymer was obtained, soluble in DMF, acetone, etc. and containing a ratio DVE:MA always less than 1:1 and having as a limit the value $1: 2$. Also, the terpolymer was always richer in MA and always poorer in AN than the monomer feed, although AN can homopolymerize readily by a free radical mechanism. NMR and IR studies showed no detectable remaining double bond in the terpolymer. In all the experiments regardless of the composition of the monomer feed used, the ratio DVE: MA in the terpolymer was always less than $1: 1$ and had the $1: 2$ structure as an upper limit. Since the ratio DVE:MA in the terpolymer varies from $1: 1$ to $1: 2$, and MA does not homopolymerize nor copolymerize with $\mathrm{AN}$ under the conditions used, 
one has to conclude that every molecule of DVE in the terpolymer chain is cyclized by a MA molecule to form the DVE:MA cyclic unit represented by $\mathrm{X} \cdot$ as follows (41):

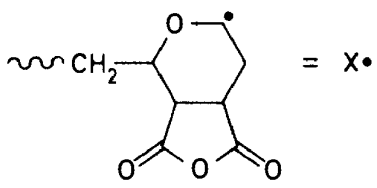

If $\mathrm{X} \cdot$ reacts with another molecule of MA (42):

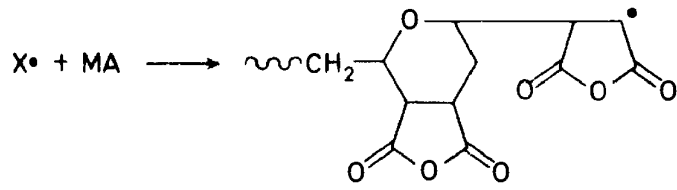

in order to give the 1:2 DVE:MA structure, this step, because of the nonreactivity of the MA radical with another molecule of MA or with AN, must be followed by an addition of a new DVE: ME couple.

If $X \cdot$ reacts with acrylonitrile (43):

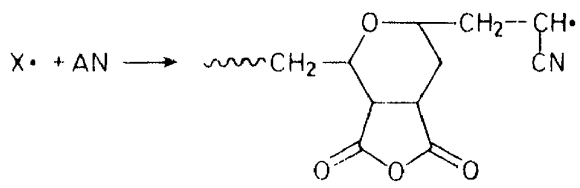

one obtains a growing chain terminated by an acrylonitrile radical; this AN radical can react either with a DVE:MA couple or with another molecule of AN. The homopolymerization of the acrylonitrile radical will result in a sequence of AN units within the chain of the terpolymer, which will increase the nitrogen content of the terpolymer and decrease the $1: 2$ regularity of the monomer pair DVE:MA, just like in the copolymerization of DVE:AN discussed here above. The structure of the terpolymer can thus be illustrated as follows (44):

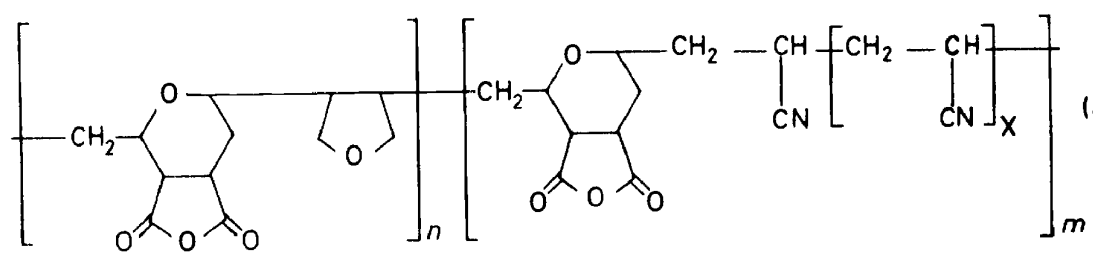

where $\mathrm{n}$ represents the 1:2 DVE:MA unit in the cycloterpolymer, and $\mathrm{m}$ the unit containing acrylonitrile. In the series of terpolymerizations in which the donor-acceptor ratio was kept constant to the $1: 2$ value, it was observed that the value of $n$ decreased with the decrease of the MA:DVE ratio in the monomer feed. The results are given in Table 6 and Figure 11. 
Table 6. Variation of the $1: 2$ DVE:MA content in the terpolymer (n) with the MA:DVE ratio in the monomer feed

\begin{tabular}{l|c|c}
\hline Run No. & $\begin{array}{c}\text { MA:DVE } \\
\text { in monomer feed }\end{array}$ & $\mathrm{n}$ in $\%$ \\
\hline T II 3 RE & 1.8 & 86.5 \\
T II 1 R3 & 1.6 & 67.9 \\
T II 4 RE & 1.4 & 71.5 \\
T II 5 RE & 1.0 & 49.3 \\
T II 2 R3 & 0.8 & 34.7 \\
T II 6 & 0.5 & 32.1 \\
\hline
\end{tabular}

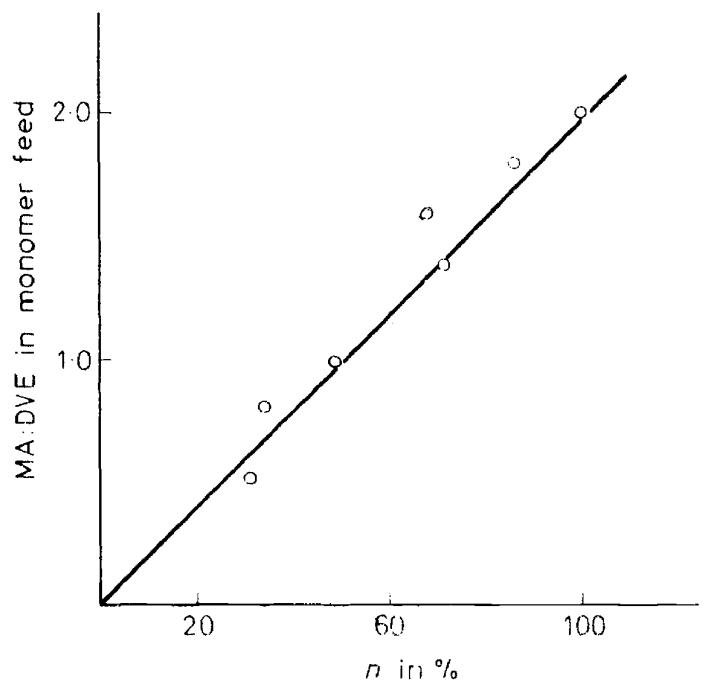

Figure 11. Variation of the $1: 2$ DVE:MA content in the terpolymer (n) versus the MA:DVE ratio in the monomer feed.

Here again in the terpolymerization system, it was observed that by diluting the polymerization solution, a decrease in the selectivity of the monomer addition was observed (Table 7). Indeed, for a monomer feed of DVE : MA : AN equal to $1: 1: 1$, the value of the $1: 2$ DVE:MA content in the terpolymer (n) decreased with dilution while the AN content increased for the same content of DVE.

Table 7.Dilution effect on the terpolymerization ${ }^{a}$ ofdivinyl ether-ma leic anhydride-acrylonitrile

\begin{tabular}{l|c|c|c|cc|c}
\hline Run No. & $\begin{array}{c}\text { Total Initial } \\
\text { Monomer } \\
\text { Concentration }\end{array}$ & $\begin{array}{c}\text { Conversion } \\
\text { in } \%\end{array}$ & $\begin{array}{c}\text { Polymer } \\
\text { AN }\end{array}$ & $\begin{array}{c}\text { Composition in } \% \\
M A\end{array}$ & DVE & $\mathrm{n}$ in \% \\
\hline T II 5 RE & $6 \mathrm{ml}^{-1}$ & 7.5 & 27.2 & 43.6 & $29 \cdot 2$ & $49 \cdot 3$ \\
T II 5 d & $1.2 \mathrm{ml}^{-1}$ & 8.8 & 31.3 & $39 \cdot 7$ & $29 \cdot 0$ & 36.9 \\
\hline
\end{tabular}

"solvent: DMF: $T=60^{\circ} \mathrm{C}:$ initrator $=\mathrm{AIBN} 1 \mathrm{~mole} \% \%$ ratio $\mathrm{DVE} / \mathrm{MA} / \mathrm{AN}=1 / 1 / 1$.

" based upon percentage of nitrogen and carboxylic content. 
Thus, it was shown in these cycloterpolymerization experiments that divinyl ether reacts preferably with maleic anhydride in order to give a cyclopolymer. This verifies the statement that was made above, that the molecular association between maleic anhydride and divinyl ether, being greater ( $e$ value greater) than the association between divinyl ether and acrylonitrile, has a greater effect in controlling the composition of the terpolymer. This molecular association, being of the nature of a chargetransfer complex, thus has a remarkable effect on the cyclopolymerization mechanism. It was also observed that while the cyclization step is very selective (DVE:MA), the next step, the addition of the monoalkene to the cyclic radical is only slightly so, which allows the inclusion of AN units in the terpolymer chain.

Both trimethylvinylsilane $\left(\mathrm{Me}_{3} \mathrm{VinSi}\right)$ and dimethyldivinylsilane $\left(\mathrm{Me}_{2} \mathrm{Vin}_{2} \mathrm{Si}\right)$ have been shown by Butler and Campus ${ }^{41}$ to form chargetransfer complexes with maleic anhydride, as shown in Figures 12 and 13. In both cases, the maximum absorbance was found to be for a molar fraction of 0.5 in maleic anhydride; hence it was concluded that the stoichiometry of the complex, even in the case of the divinyl compound is $1: 1$. Application of the method of least squares to the equation of Hanna and Ashbaugh ${ }^{36}$ yielded a more exact determination of $K$ and $\Delta_{A D}^{A}$, the results of which are shown in Table 8.

$\mathrm{Me}_{2} \mathrm{Vin}_{2} \mathrm{Si}_{1} \mathrm{Ma}$

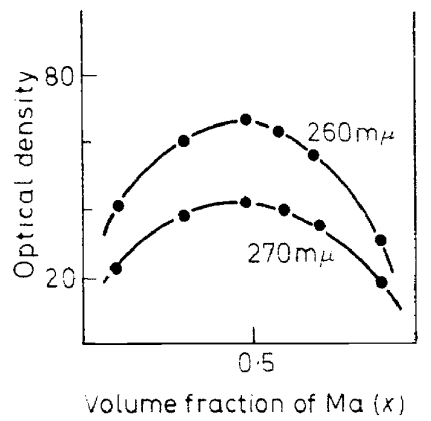

$\mathrm{Me}_{3} \mathrm{VinSI-Ma}$

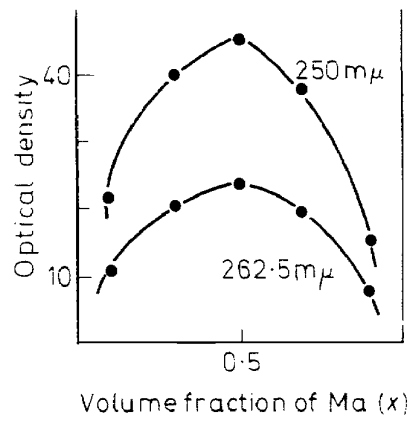

Figure 12. U.V. determination of the stoichiometric composition of the charge-transfer complexes( solvent: $\mathrm{CHCl}_{3}$ )

Despite the fact that silicon is less electronegative than carbon, it is able to withdraw $\pi$-electrons from an unsaturated system to which it is bonded. Such behaviour is generally understood as resulting from the fact that silicon is a second row element and that it thus has vacant $d$-orbitals which can be the site of the transfer of charge towards silicon. A variety of evidence supports $^{42}$ this $d \pi-p \pi$ bonding between the silicon atom and a $\pi$-electron system; among them note studies of dipole moments and studies of proton magnetic resonance spectra. A detailed study of the NMR spectra of $\mathrm{Me}_{3} \mathrm{VinSi}$ and $\mathrm{Me}_{2} \mathrm{Vin}_{2} \mathrm{Si}$ as well as phenylvinylsilane derivatives reported by Hobgood and Goldstein ${ }^{43,44}$, concludes that the $d \pi-p \pi$ bonding is responsible, at least for a part, of the considerably low position of the shifts of the vinyl 

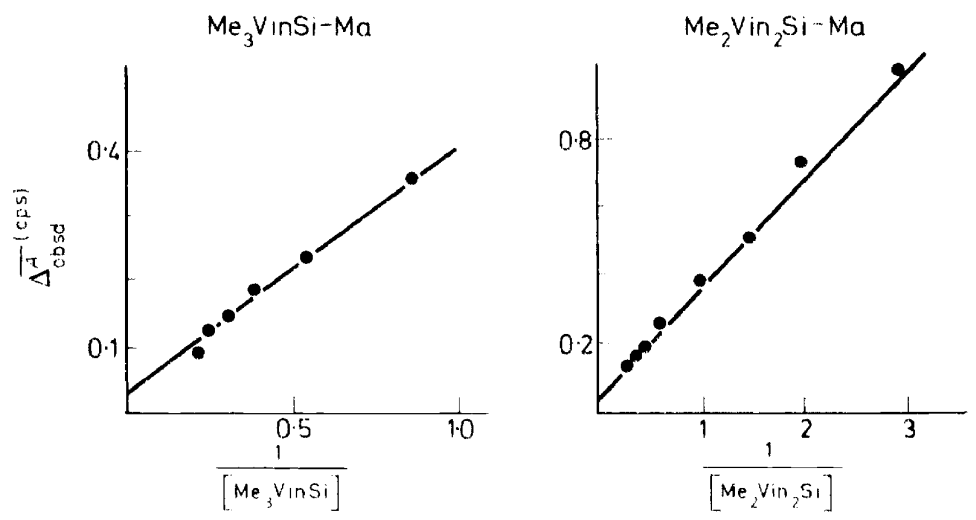

Figure 13. NMR determination of the equilibrium constant of the charge-transfer complexes (solvent: $\mathrm{CDCl}_{3}, T=23$ )

Table 8. NMR determination ${ }^{a}$ of the equilibrium constant of complexation of the charge-trasfer complexes of $\mathrm{Me}_{3} \mathrm{VinSi}-\mathrm{MA}$ and $\mathrm{Me}_{2} \mathrm{Vin}{ }_{2} \mathrm{Si}$ MA with maleic anhydride

\begin{tabular}{c|c|c}
\hline $\begin{array}{c}\text { Complex with maleic } \\
\text { anhydride }\end{array}$ & $\Delta_{A D}^{A} \mathrm{cps}$ & $K \mathrm{~lm}^{-1}$ \\
\hline $\mathrm{Me}_{3} \mathrm{VinSi}-\mathrm{MA}$ & $42 \cdot 3$ & - \\
$\mathrm{Me}_{2} \mathrm{Vin}_{2} \mathrm{Si}-\mathrm{MA}$ & $29 \cdot 5$ & $0 \cdot 061$ \\
\hline
\end{tabular}

solvent $=\mathrm{CDCl}_{3}: T=23 \mathrm{C}$.

protons of silane derivatives compared with the corresponding shifts in hexene-1. This $d \pi-p \pi$ bonding leads to a decrease of the electronic density of the double bonds of vinylsilanes, which would decrease the strength of the charge-transfer complexes compared with the carbon analogues, but we do not have at the present time results to report on the complex of $3,3^{\prime}$ dimethyl-1,4-pentadiene and maleic anhydride. By comparison (see Table 9) with the $\mathrm{C}-\mathrm{T}$ complexes studied in the case of ethylvinylether (EVE) and divinylether (DVE), it was observed that the maximum absorptions in the case of vinylsilane complexes are at lower wavelength than those of the vinylethers.

Since for a series of complexes of different donors with the same acceptor, $\lambda_{\max }$ is linearly related to the ionization potential of the donor ${ }^{35}$ it was

Table 9. Comparison between vinylsilanes and vinylethers complexes with maleic anhydride

\begin{tabular}{l|c|c}
\hline \multicolumn{1}{c|}{ Complex } & $\lambda_{\max .} m \mu$ & $K 1 \mathrm{~m}^{-1}$ \\
\hline $\mathrm{Me}_{3} \mathrm{VinSi}-\mathrm{MA}$ & $<250$ & 0.061 \\
$\mathrm{Me}_{2} \mathrm{Vin}{ }_{2} \mathrm{Si}-\mathrm{MA}$ & $<250$ & $0 \cdot 107$ \\
$\mathrm{EVE}-\mathrm{MA}$ & 277.5 & 0.041 \\
$\mathrm{DVE}-\mathrm{MA}$ & -278 & 0.036 \\
\hline
\end{tabular}


concluded that the ionization process required less energy in the case of vinylethers compared with vinylsilanes, which can be well understood by the fact that the double bonds of the vinylethers are more electron rich, due to the delocalization of the non-bonding pairs of the oxygen atom towards the vinyl groups. The opposite effect is observed in the $d \pi-p \pi$-bonding in the case of vinylsilanes.

On the other hand, if we compare the stability of these complexes, we observe that the silane complexes are more stable than those of the vinylethers. This increase in stability can perhaps be attributed to this $\mathrm{d} \pi-p \pi$ bonding characteristic of compounds containing silicon attached to unsaturated systems.

Investigation of the 3,3-dimethyl-1,4-pentadiene-maleic anhydride complex will give a better system for comparison.

\section{Copolymerization of trimethylvinylsilane with maleic anhydride}

Table 10 shows data for copolymerization of trimethylvinylsilane and maleic anhydride.

Table 10. Trimethylvinylsilane $\left(\mathbf{M}_{1}\right)$-Maleci anhydride $\left(\mathbf{M}_{2}\right)$ copolymers ${ }^{a}$.

\begin{tabular}{l|c|c|c|c|c|c}
\hline Run no. & $\begin{array}{c}\mathrm{M}_{2} \\
\text { (monomer } \\
\text { mole ratio) }\end{array}$ & $\begin{array}{c}\text { Reaction } \\
\text { time. hrs. }\end{array}$ & $\begin{array}{c}\text { Conversion } \\
\%\end{array}$ & $\begin{array}{c}\text { Rate of } \\
\text { polymerization } \\
\text { conv/time } \times 10^{3}\end{array}$ & $\% \mathrm{Si}^{b}$ & $m_{2}$ \\
\hline F I & 0.8 & 115 & 3.0 & 26 & 12.93 & 0.547 \\
F II & 0.6 & 96 & 8.4 & 87 & 14.50 & 0.492 \\
F III & 0.5 & 91.25 & 12.0 & 122 & 14.05 & 0.508 \\
F IV & 0.4 & 96 & 8.7 & 91 & 14.28 & 0.504 \\
F V $^{d}$ & 0.2 & 115 & 5.6 & 48 & 14.04 & 0.508 \\
\hline
\end{tabular}

a Solvent of copolymerization = benzene; $T=60$; in itiator: AIBN $1 \% /$ mole: $[\mathrm{M}]_{T}=4 \mathrm{ml}^{-1}$ (constant).

"The composition of the copolymer is based upon the silicon content; $1: 1$ copolymer requires $14.15 \% \mathrm{Si}$

$[\eta]=0.06 \mathrm{dl} / \mathrm{g}(30$, acetone $)$.

${ }^{d}[\eta]^{\prime}=0.08 \mathrm{dl} / \mathrm{g}(30$, acetone $)$

Over a relatively wide range of initial monomer composition, the molar fraction of MA in the copolymer remains constant and equal to 0.5 except for the most dilute solution in $\mathrm{Me}_{3} \mathrm{VinSi}$ where a value of 0.547 was found for $\mathrm{m}_{2}$. These values are quite consistent with an alternating copolymer. The fact that two monomers give an alternating copolymer while they do not homopolymerize under the same conditions is not new; the first example was reported in $1930^{45}$ in the case of the alternating free-radical copolymerization of stilbene with maleic anhydride.

It has been observed by some authors ${ }^{29}$ that the rate of the alternating free-radical copolymerization is maximum for a monomer feed ratio equal to $1: 1$, the medium in which the concentration of the charge-transfer complex of 1:1 stoichiometry is higher. Similar behaviour was observed in this case (Figure 14).

Such observation can support to some extent the participation of the charge-transfer complex formed between $\mathrm{Me}_{3} \mathrm{VinSi}$ and $\mathrm{MA}^{46}$ in its alter- 


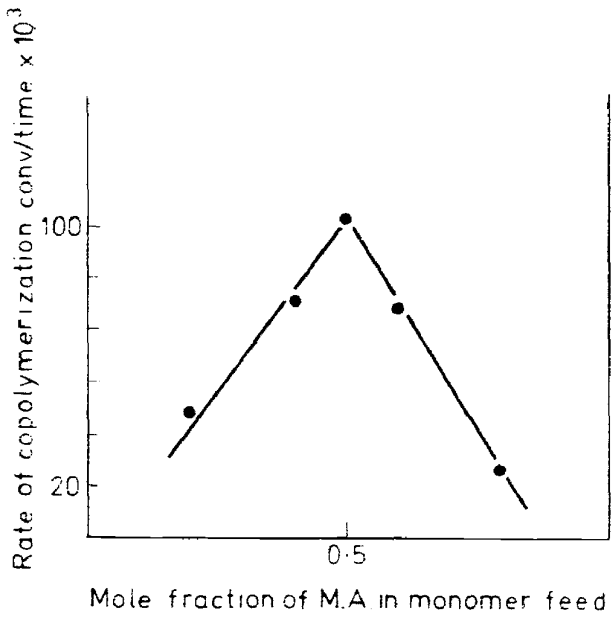

Figure 14. Dependence of the rate of copolymerization upon the monomer feed ratio in the copolymerization of $\mathrm{Me}_{3} \mathrm{VinSi}$ and M.A. (AIBN, benzene, $60^{\circ}$ ).

nating free-radical copolymerization, which could be reduced, as it was proposed by Iwatsuki and Yamashita ${ }^{29}$, to the homopolymerization of the charge-transfer complex formed between the comonomers.

\section{Copolymerization of dimethyldivinylsilane with maleic anhydride}

The data for the copolymerization of dimethyldivinylsilane with maleic anhydride are given in Table 11.

Table 11. -Dimethyldivinylsilane $\left(\mathrm{M}_{1}\right)$-maleic anhydride $\left(\mathrm{M}_{2}\right)$ copolymers ${ }^{a}$.

\begin{tabular}{|c|c|c|c|c|c|c|}
\hline Run No. & $\begin{array}{c}\mathrm{M}_{2} \\
\text { Monomer } \\
\text { mole ratio) }\end{array}$ & $\begin{array}{l}\text { Reaction } \\
\text { time: hrs. }\end{array}$ & $\begin{array}{c}\text { Conversion } \\
\%\end{array}$ & $\% \mathrm{Si}^{b}$ & $\mathrm{~m}_{2}$ & conv. $/ \mathrm{hr}$. \\
\hline D 1 & 0.20 & $27 \cdot 5$ & $5 \cdot 3$ & $9 \cdot 30$ & 0.660 & $0 \cdot 194$ \\
\hline $\mathrm{D} 2^{\mathrm{c}}$ & 0.33 & 27 & $8 \cdot 1$ & $9 \cdot 29$ & 0.660 & $0 \cdot 300$ \\
\hline D 3 & 0.50 & 24 & $7 \cdot 6$ & $9 \cdot 12$ & 0.666 & 0.317 \\
\hline D 4 & 0.60 & 23 & $10 \cdot 8$ & $9 \cdot 27$ & 0.661 & 0.469 \\
\hline D 5 & 0.67 & 22 & $12 \cdot 0$ & $8 \cdot 99$ & 0.672 & 0.545 \\
\hline $\mathrm{D} 6^{d}$ & 0.75 & 21 & $10 \cdot 1$ & $9 \cdot 13$ & 0.666 & 0.481 \\
\hline D 7 & 0.80 & 19 & $10 \cdot 6$ & 8.97 & 0.671 & 0.558 \\
\hline
\end{tabular}

Over a wide range of initial monomer composition, the molar fraction of maleic anhydride in the copolymer is equal to the predicted value for $2: 1$ molar alternating copolymers. The copolymers were insoluble in the polymerization medium (benzene), but were soluble in solvents such as acetone and DMF from which they were precipitated twice into anhydrous ether before analysis. The solubility of these copolymers in organic solvents 
rules out the possibility of formation of a cross-linked polymer. The 1:2 $\mathrm{Me}_{2} \mathrm{Vin}_{2} \mathrm{Si}$ :MA content, the non-homopolymerizability of MA and the absence (based on IR and NMR studies) of any remaining double bond in the copolymers permit such a structure as (45) for the copolymer to be ruled out :

$$
[\begin{array}{l}
\mathrm{FH}_{2}-\mathrm{CH} \\
\mathrm{CH}_{3}=\mathrm{SH}_{\mathrm{O}}
\end{array} \underbrace{}_{\mathrm{CH}=\mathrm{CH}_{2}} \mathrm{CH}_{0}
$$

On the other hand, the position and the integration of the NMR peaks of the copolymers are quite consistent with the 1:2 $\mathrm{Me}_{2} \mathrm{Vin}_{2} \mathrm{Si}$ :MA cyclic unit as defined previously ${ }^{6-8}$ for pairs of monomers such as divinyl ether: maleic anhydride and divinyl ether: fumaronitrile. The structure of the copolymer can thus be illustrated as follows (46):

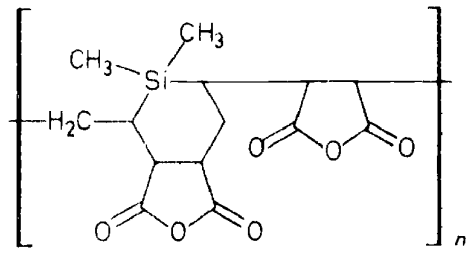

Since the ratio of diene to olefin is constantly equal to $1: 2$ the copolymer composition equation(s) as a function of monomer feed in terms of the reactivity ratio parameters is reduced to $n=1 / 2$.

The possibility of the participation of the charge-transfer complex between comonomers in the mechanism of cyclopolymerization has been discussed earlier. It was also pointed out that the $\mathrm{C}$. $\mathrm{T}$. complexes between vinylsilanes and maleic anhydride, although of weak strength have a relatively high stability, which improves the concentration of the C. T. complex in the polymerization medium. The stability of the complex and the regularity of the $1: 2$ structure seems to be related since in this case we have a very regular $1: 2$ copolymer while in the case of divinyl ether-fumaronitrile less stable complex, the value of $\mathrm{m}_{2}$ ranges from 0.55 to 0.63 , and in the case of of divinyl ether acrylonitrile, where no obvious interaction of the $\mathrm{C}$. T. nature occurred, an even less regularity is obtained.

\section{ACKNOWLEDGEMENTS}

The major portion of the research results reported in this paper from the University of Florida laboratories was supported by the National Institutes of Health under Grant No. CA 06838 for which we are grateful. The author is also grateful to the National Science Foundation for a financial grant to help defray the costs of his travel to Prague to present this paper. 


\section{References}

1 G. B. Butler and F. L. Ingley. J. Am. Chem. Soc. 73, 895 (1951).

${ }^{2}$ H. Staudinger and W. Heuer. Ber. 67, 1159 (1934).

3 G. B. Butler and R. J. Angelo. J. Am. Chem. Soc. 79, 3128 (1957).

4 G. B. Butler, A. Crawshaw and W. L. Miller. J. Am. Chem. Soc. 80, 3615 (1958).

${ }^{5}$ G. B. Butler. Encyclopedia of Polymer Science and Technology 4, 568. John Wiley and Sons, Inc. (1966).

${ }^{6}$ G. B. Butler. Paper No. 15, Division of Polymer Chemistry, 133rd Meeting of Americal Chemical Society, San Francisco, Calif., April, 1958. Abstracts of Papers p. 6R.

7 G. B. Butler. J. Polymer Sci. 48, 279 (1960).

8 J. M. Barton, G. B. Butler and E. C. Chapin. J. Polymer Sci. A3, 501 (1965).

${ }^{9}$ G. B. Butler. Paper No. 77, Div. of Polymer Chemistry, 134th Meeting American Chemical Society, Chicago, Ill. Sept., 1968, Abstracts of papers p. 32T.

10 G. B. Butler. U.S. Pat. 3,320.216; Pat Re. 26, 407 (to Calgon Corp.)

12 P. W. Tidwell and G. A. Mortimer. Paper presented at 145th American Chemical Society Meeting, New York, Septmber 1963; Polymer Preprints, 4, No. 2, 236 (1963).

13 G. B. Butler and R. B. Kasat. J. Polymer Sci. A3, 4205 (1965).

${ }_{14}$ G. B. Butler, A. J. Sharpe, Jr. and R. B. Kasat. In press.

15 G. B. Butler, G. Vanhaeren and M. F. Ramadier. J. Polymer Sci. A-1 5, 1265 (1967).

${ }^{16}$ G. B. Butler and K. C. Joyce. J. Polymer Sci. C, (No. 22) 45 (1968).

17 R. D. Kimbrough. J. Polymer Sci. B 2, 85 (1964).

18 K. Fukiu, K. Hayashi, T. Yonezawa, C. Nagata and S. Okamura. J. Polymer Sci. 20, 537 (1956).

19 H. A. Benesi and J. Hildebrand. J. Am. Chem. Soc. 71, 2703 (1949).

20 R. S. Mulliken. J. Am. Chem. Soc. 74, 811 (1952).

21 E. M. Kosower. Progress in Physical Organic Chemistry, 3, 81, Wiley-Interscience (Reactions through Charge-Transfer Complexes, p. 82) (1965).

22 R. L. Scott. Rec. Trav. Chim. 75, 787 (1956).

23 W. B. Person. J. Am. Chem. Soc. 87, 167 (1965).

24 P. Bartlett and K. Nozaki. J. Am. Chem. Soc. 68, 1495 (1946).

25 W. Barb. Trans. Faraday Soc. 49, 143 (1953).

26 C. Walling, E. Briggs, K. Wolfstirn and F. R. Mayo. J. Am. Chem. Soc. 70, 1537 (1948).

27 R. Robson, P. W. Grubb and J. A. Baltrop, J. Chem. Soc. 2153 (1964).

28 S. Iwatsuki and Y. Yamashita. Makromol. Chem. 89, 205 (1965).

29 S. Iwatsuki and Y. Yamashita. Makromol. Chem. 102, 232 (1967).

30 G. B. Butler and A. F. Campus. J. Polymer Sci. A1 9, 545 (1970).

${ }^{31}$ P. Job. Compt. Rend., 180, 928 (1925); Ann. Chim. Phys., 9, 113 (1928).

32 W. C. Vosburgh and G. R. Cooper. J. Am. Chem. Soc., 63437 (1941).

33 J. K. Williams, D. W. Wiley and B. C. McKusick. J. Am. Chem. Soc. 84, 2210 (1962).

34 C. C. Price and T. C. Schwan. J. Polymer Sci. 16, 577 (1955).

${ }^{35} \mathrm{G}$. Briegleb. Elektronen-Donator-Acceptor Komplexe Springer Verlag Berlin-Gottingen Heidelbus (1961).

${ }^{36}$ M. W. Hanna and A. L. Ashbaugh. J. Phys. Chem. 68, 811 (1964).

37 R. Foster and C. A. Fyfe. Trans. Faraday Soc. 61, 1626 (1965).

${ }^{38}$ C. Aso and S. Ushio. Kogyo Kagaku Zasshi. 65, 2085 (1962).

39 G. E. Ham. Copolymerization Interscience Publishers, New York (1964).

${ }^{40}$ F. R. Mayo, F. M. Lewis and C. Walling. J. Am. Chem. Soc. 70, 1529 (1948).

41 G. B. Butler and A. F. Campus. J. Polymer Sci. A1, 9, 523 (1970).

42 C. Eaborn. Organosilicon Compounds New York, Academic Press Inc., Publishers, p. 91-113 (1960).

43 R. T. Hobgood, J. H. Goldstein and G. S. Reddy. J. Chem. Phys., 35, 2038 (1961).

44 R. T. Hobgood and J. H. Goldstein. Spectrochim. Acta. 19, 321 (1963).

45 Theodor Wagner-Jauregg, Ber. 63, 3213 (1930).

${ }^{46}$ N. S. Nametkin, V. S. Khotimskii and S. G. Durgaryan. Doklady. Akad. Nauk, S.S.S.R. 166, 1118 (1966). 